\title{
Article
}

\section{Construction Progress and Aviation Flight Test of BDSBAS}

\author{
Weiguang Gao ${ }^{1}$, Yueling Cao ${ }^{2}$, Cheng Liu ${ }^{1, *}$, Jun Lu ${ }^{1}$, Bo Shao ${ }^{3}$, Shuai Xiong ${ }^{3}$ and Chengeng Su ${ }^{1}$ \\ 1 Beijing Institute of Tracking and Telecommunication Technology, Beijing 100094, China; \\ gaowg@beidou.gov.cn (W.G.); lujun@beidou.gov.cn (J.L.); sucg@beidou.gov.cn (C.S.) \\ 2 Shanghai Astronomical Observatory, Chinese Academy of Sciences, Shanghai 200030, China; \\ caoyueling@shao.ac.cn \\ 3 The 20th Research Institute of China Electronics Technology Group Corporation, Xi'an 710068, China; \\ shaobo@cetc-pnt.com (B.S.); xiongshuai@cetc-pnt.com (S.X.) \\ * Correspondence: liucheng@beidou.gov.cn
}

check for updates

Citation: Gao, W.; Cao, Y.; Liu, C.; Lu, J.; Shao, B.; Xiong, S.; Su, C.

Construction Progress and Aviation

Flight Test of BDSBAS. Remote Sens. 2022, 14, 1218. https://doi.org/

$10.3390 /$ rs 14051218

Academic Editors: Qile Zhao and Yunbin Yuan

Received: 21 January 2022

Accepted: 28 February 2022

Published: 2 March 2022

Publisher's Note: MDPI stays neutral with regard to jurisdictional claims in published maps and institutional affiliations.

Copyright: () 2022 by the authors Licensee MDPI, Basel, Switzerland. This article is an open access article distributed under the terms and conditions of the Creative Commons Attribution (CC BY) license (https:// creativecommons.org/licenses/by/ $4.0 /)$.

\begin{abstract}
As an important part of the BeiDou global navigation satellite system (BDS-3), the BeiDou satellite-based augmentation system (BDSBAS) aims to provide a high-integrity navigation service for users in China and its surrounding areas. At present, BDSBAS has completed the preliminary construction of the system and formed the single frequency (SF) augmentation service. The paper introduces the composition and working process of BDSBAS, and expounds the solution and performance evaluation methods of the BDSBAS SF service. Tests based on a general aviation aircraft were carried out at Caihu Airport in Shenyang, China, which simulated the aircraft's take-off and landing operation during the approach phase and the transition flight operation during the en-route phase. On this basis, the BDSBAS SF service performance was analyzed and evaluated. The horizontal positioning errors of the three flight tests are 1.62, 1.27, and $1.49 \mathrm{~m}$, respectively, and the vertical positioning errors are 4.38, 4.30, and $4.04 \mathrm{~m}$, respectively. In the first two tests, the APV-I availability and continuity of the service reach $100 \%$. In the last test, a receiver false alarm event occurred, resulting in an APV-I availability and continuity of $99.993 \%$ and $99.989 \%$, respectively. The event was confirmed to be caused by some aviation environmental factors and was not related to the system service. No integrity events occurred during the tests. The test results show that the positioning accuracy, availability, and integrity of the BDSBAS SF service meet the APV-I level requirements of the ICAO standards, which preliminarily illustrates the ability of BDSBAS to be used in the field of civil aviation.
\end{abstract}

Keywords: GNSS; BeiDou; BDS-3; BDSBAS; SBAS; APV-I; CAT-I

\section{Introduction}

As an important augmentation technique of GNSS, the satellite-based augmentation system (SBAS) was originally designed for aviation use to provide the capability for increased availability and accuracy in position reporting, and to allow for more time for uniform and high quality air traffic management [1]. Further, due to its reliability, high precision, and convenience, SBAS has become a relied upon utility for a number of nonaviation uses such as shipping, mapping and survey, farming, and even mass consumer GNSS terminals, and is becoming more and more closely related to our everyday lives.

Since its first commission for service in July 2003, WAAS continues to upgrade and optimize its satellites, ground facilities, algorithms, etc., and has provided lessons in support of development of other SBASs in the world [2-4]. Currently, the WAAS localizer performance with vertical guidance (LPV)/LPV-200 operation has almost covered the entire North America region, and RNP 0.3 operation covers North, Central, and parts of South America [5,6]. Most of the airports throughout the National Airspace System (NAS) contain WAAS procedures, and more than $4700 \mathrm{LPV} / \mathrm{LP}$ procedures have been published. Since 2006, WAAS aircraft equipage has increased each year. As of 2019, more than 
125,000 aircraft have been equipped with WAAS receivers [7]. In the summer of 1994, Stanford performed WAAS flight trials to provide WAAS operational experience [8]. The flight trials used three WAAS reference stations (WRSs), which Stanford installed for the FAA in the western United States, and also used Professor David Powell's Piper Dakota to fly WAAS precision approaches to an un-instrumented airport (Palo Alto). The WAAS corrected pseudo-ranges are used to calculate the aircraft location and glide path deviations. This entire process occurs in real time and yields vertical errors better than $3 \mathrm{~m} 95$ percent of the time.

EGNOS provides three types of services: open service (OS) since October 2009 [9], safety of life (SoL) service, since March 2011 [10], and EGNOS data access service (EDAS) service, since July 2012 [11]. The availability of EGNOS's NPA operation in all European Civil Aviation Conference (ECAC) regions exceeds 0.999, and the APV-I and LPV200 operations in most of ECAC landmasses exceed 0.99 [12]. In May 2016, EGNOS completed the first LPV200 approach at the Paris-Charles de Gaulle airport. As of today, EGNOS has more than 331 LPV programs, and more than 167 LPV200 programs, serving more than 167 airports [12]. In recent years, EGNOS has continued to promote the expansion of coverage and service scope, for example, in countries or regions such as South Africa, Ukraine, the Middle East, and the Mediterranean [13]. Aviation flights test were conducted in [14] by using a Cessna 172 aircraft equipped with an EGNOS airborne receiver. Among them, the positioning error of the test at the EPDE military aerodrome in Depblin is less than $2.1 \mathrm{~m}$, and the integrity of positioning does not exceed $19 \mathrm{~m}$; the postioning error of the test at the Depułtycze Królewskie aerodrome EPCD is less than $2.1 \mathrm{~m}$, and the integrity of positioning does not exceed $19 \mathrm{~m}$. Moreover, the availability parameter was found to be $100 \%$. Also, no intervals of loss of the continuity of operation of the EGNOS system were recorded.

Japan's SBAS, named as MSAS (MTAST (Multi-functional Satellite) Satellite-Based Augmentation System), began operation in September 2007. After over 10 years' operation, the first two GEOs, named MTSAT-1R and MTSAT-2, respectively, have been decommissioned in 2015 and 2020 [15]. Since 2020, MSAS GEOs have been replaced by QZSS GEOs for SBAS service as a part of the QZSS program [16]. Due to the ionosphere condition of the low magnetic latitude of the service area, MSAS has provided horizontal navigation only for en-route to NPA (non-precision approach) operations since the beginning [17]. However, recently research for vertical guidance has been conducted with the assumption of 13 domestic ground monitor stations for MSAS in 2020 and later. This upgrade of MSAS will provide LPV operation at the most airports in Japan and LPV-200 at some major airports [18].

India's GAGAN (GPS Aided GEO Augmentation Navigation) was certified in two steps: on 30 December 2013 for RNP 0.1 operations, and on 21 April 2015 for APV-I operations $[19,20]$. In order to meet the set object of APV-I over the India land mass, GAGAN has developed an appropriate region-specific ionosphere model, which makes it the first SBAS in the world to be certified for APV-I operation in the equatorial region [21]. In aviation applications, the Indian government requires that the new aircraft purchased after 1 January 2019 be equipped with SBAS equipment, and encourages the retrofitting of the existing fleet by incentivizing airline operators [20,22].

Russia's SDCM and GLONASS are integrated constructions to provide users with GLONASS-based services. Currently, the SDCM testing work has been completed, and the system is at the initial stage of certification. According to the plan, SDCM will use three Luch-5M GEOs to replace the original three GEOs from 2020, and add an additional Luch-5M GEO in $160^{\circ} \mathrm{E}$ orbit to jointly support SBAS L5. The four core GNSS constellations are all considerations for the SDCM DFMC service, and the expected positioning accuracy is up to $0.5 \mathrm{~m}$ [23].

South Korea government has also developed its own SBAS, named the Korea Augmentation Satellite System (KASS), with the goal of providing APV-I operation as early as from year 2022 [24]. Since 2020, KASS has begun to provide initial open service. The 
assessed availability performance of the initial service is more than $99 \%$, and the assessed positioning accuracy in the horizontal and vertical directions is $0.92 \mathrm{~m} \mathrm{(95 \% )} \mathrm{and} 1.61 \mathrm{~m}$ (95\%), respectively [25]. Currently, KASS is in the system certification stage. According to the plan, operation certification will be started simultaneously in 2021 [26].

At present, all of the SBASs in service are single-frequency (SF) SBAS which augments GPS L1 C/A. Due to the impact of ionospheric anomalies, SF SBAS service performance has not met the requirements of Category I precision approach (CAT-I). Only WAAS and EGNOS have reached LPV-200. To reduce the impact of ionospheric anomalies on service performance and enhance the service performance by using multi-GNSSs which can improve the geometric layout of constellations, the International Civil Aviation Organization (ICAO) DFMC SBAS SARPs (DS2) working group has developed the draft of Dual-Frequency Multi-Constellation (DFMC) SBAS international standards. The ICAO Air Navigation Commission (ANC) has forwarded the draft of DFMC SBAS SARPs to States parties and relevant international organizations for comments.

As one of the components and service types of BDS-3, BDSBAS is of great significance to improving the navigation integrity of aviation users in China and surrounding areas [27]. As early as 2012, China began to carry out system design and formulate development plans. In 2015, it began to actively participate in the joint research and formulation of SBAS international standards and conduct surveys and site selection of monitoring stations [28]. In October 2017, at the meeting of the ICAO DS2 working group, BDSBAS was included in the DFMC SBAS SARPs as one of the main service providers of SBAS [29]. In November 2018, the first BDSBAS GEO satellite was launched, and the system integration and testing work officially began. In July 2020, all of the three GEO satellites began to operate in orbit [30], and the "final" PRN codes were successfully applied for from the GPS PRN Coordination Office (PRNCO) of the US Air Force in August [31].

At present, BDSBAS has completed the preliminary construction and is carrying out performance testing, and the first phase of BDSBAS will provide the SF service to augment the GPS satellites. We introduce the system composition and work flow of BDSBAS. At Caihu Airport in Shenyang, China, the general aviation aircraft was used to carry out the aviation flight test to simulate the take-off and landing operation during the approach phase and the transition flight operation during the enroute phase. The aeronautical performance of the SF service was analyzed and evaluated. The results show that the SF service performance during the flight test can meet the APV-I level requirements. A false alarm event was discovered during the test due to some unknown aviation environmental factors, which reminded us that we need to strengthen the detection and protection capabilities of aviation electromagnetic interference in the development of BDSBAS aviation airborne terminals. This contribution can help the majority of GNSS and SBAS users, as well as related engineering R\&D and scientific research personnel, to better understand the latest construction progress of BDSBAS, and provide experience and reference for the upcoming BDSBAS civil aviation airworthiness certification work.

In the following sections, the system architecture and operation flow of BDSBAS is presented first. Afterward, the user algorithm of the BDSBAS SF service, including the use of the corrections and degradation parameters and the generation of the protection level is illustrated. Then, the performance evaluation method of the SBAS service is described, including four aspects: positioning accuracy, service availability, continuity, and integrity. Subsequently, the test environment is set up, and the aeronautical flight tests are constructed to evaluate and analysis the performance of the service. Finally, the conclusions are drawn, including BDSBAS' next plan. 


\section{Overview of BDSBAS}

BDSBAS shares the GEOs and ground segment facilities with BDS-3. At present, three GEO satellites have been launched and are working in orbit; the ground section facilities have been almost completed, and BDSBAS has formed the initial operational capability.

\subsection{System Architecture}

BDSBAS is composed of three parts: a space segment, ground segment and user segment (as shown in Figure 1).

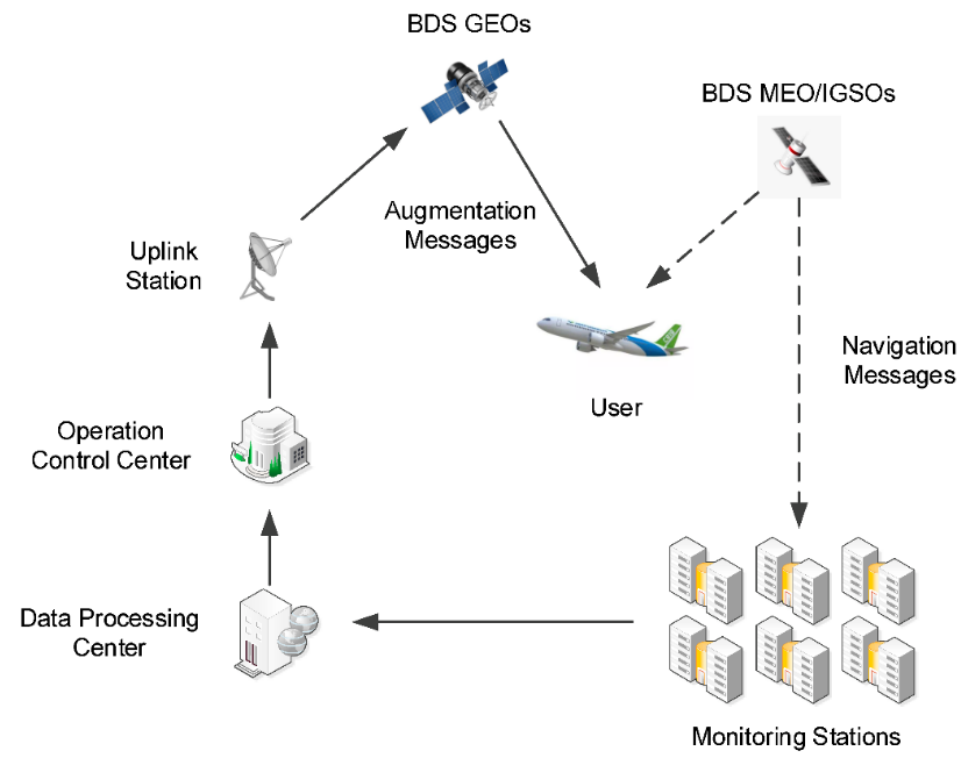

Figure 1. Architecture of BDSBAS.

The BDSBAS space segment includes three geosynchronous earth orbit (GEO) satellites, which broadcast SF augmentation information through B1C frequency and DFMC augmentation information through B2a frequency. The specific information of BDSBAS GEOs is shown in Table 1.

Table 1. PRN codes and orbital slots of BDSBAS GEOs [31].

\begin{tabular}{cccc}
\hline Satellite & PRN Code Number & Orbital Slot & Launch Date \\
\hline GEO-1 & 130 & $140 \mathrm{E}$ & 1 November 2018 \\
GEO-2 & 144 & $80 \mathrm{E}$ & 9 March 2020 \\
GEO-3 & 143 & $110.5 \mathrm{E}$ & 23 June 2020 \\
\hline
\end{tabular}

The ground segment consists of 1 operation control center (OCC) in Beijing, 2 data processing centers (DPC) in Beijing and Xi'an, 3 uplink stations (US) and 30 monitoring stations (MS) in China and overseas. A total of 27 of the 30 MSs are evenly distributed in cities such as Beijing, Guangzhou, Xi'an, and Changsha in mainland China, as shown in Figure 2. The other 3 MSs are deployed overseas, which are located in Kamchatka, Irkutsk and Obninsk of Russia. The specific coordinates and observation data of the MSs are planned to be released after the system has passed the civil aviation certification. Each MS contains three multi-frequency and multi-mode monitoring receivers, meteorological equipment and a rubidium atomic clock [32]. At present, the ground section facilities of BDSBAS have been almost completed, and the system already has the capability for initial operation. 


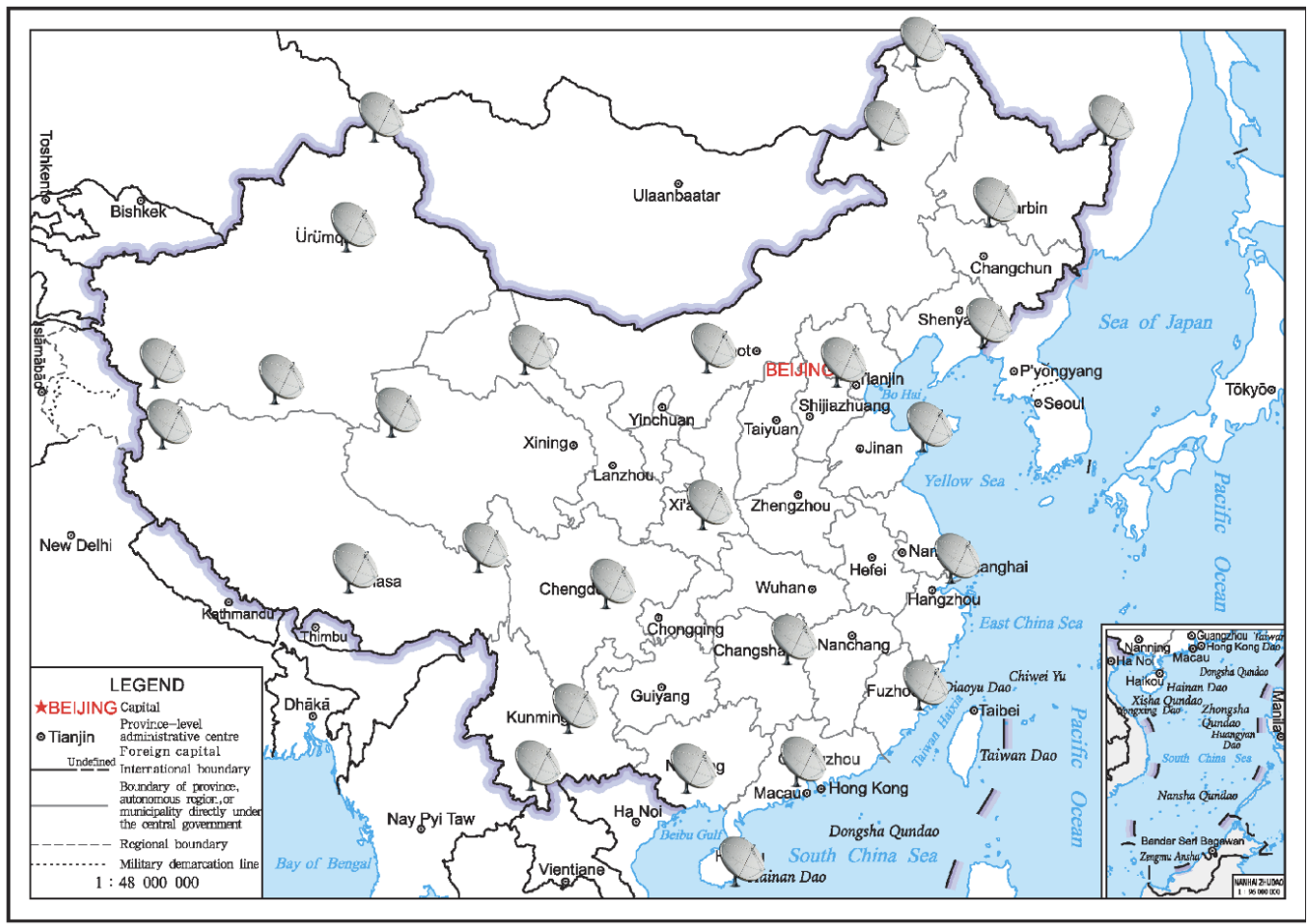

Figure 2. The $27 \mathrm{MSs}$ located in mainland China.

The user segment refers to BDSBAS terminals used in civil aviation, maritime, railway and other applications. User uses the correction information from the messages to improve accuracy and the integrity information from the messages to calculate the protection level, providing users with better navigation performance and integrity guarantee. BDSBAS user equipment used in civil aviation shall meet the requirements of RTCA DO-229 [33].

\subsection{Operation Flow}

The operation and process flow of BDSBAS is shown in Figure 3. The three monitoring receivers of the MS are used to collect the raw observations of pseudo-ranges and carriers of GNSS satellites at each signal frequency in real time, and the meteorological data are collected by meteorological equipment and then transmitted to the DPC through the ground communication network. The DPC performs redundancy inspection, preprocessing, differential corrections calculation for orbit corrections, clock corrections, grid ionospheric vertical delay (GIVD), integrity information calculation for user differential range error (UDRE), dual frequency range error (DFRE), grid ionospheric vertical error (GIVE), degradation parameters, and consistency checking processing on the raw observations to generate augmentation information before transmitting it to the OCC. The OCC arranges the augmentation information in a standard format, forms the augmentation messages, and transmits it to the US. The US uploads the augmentation messages to the BDSBAS GEOs and broadcast the messages in the service area. Finally, the user receives the GNSS observations and the BDSBAS augmentation messages in real time, and simultaneously performs augmentation positioning and protection level calculation. On this basis, the protection level and the alarm level are compared to realize the integrity alarm function. 

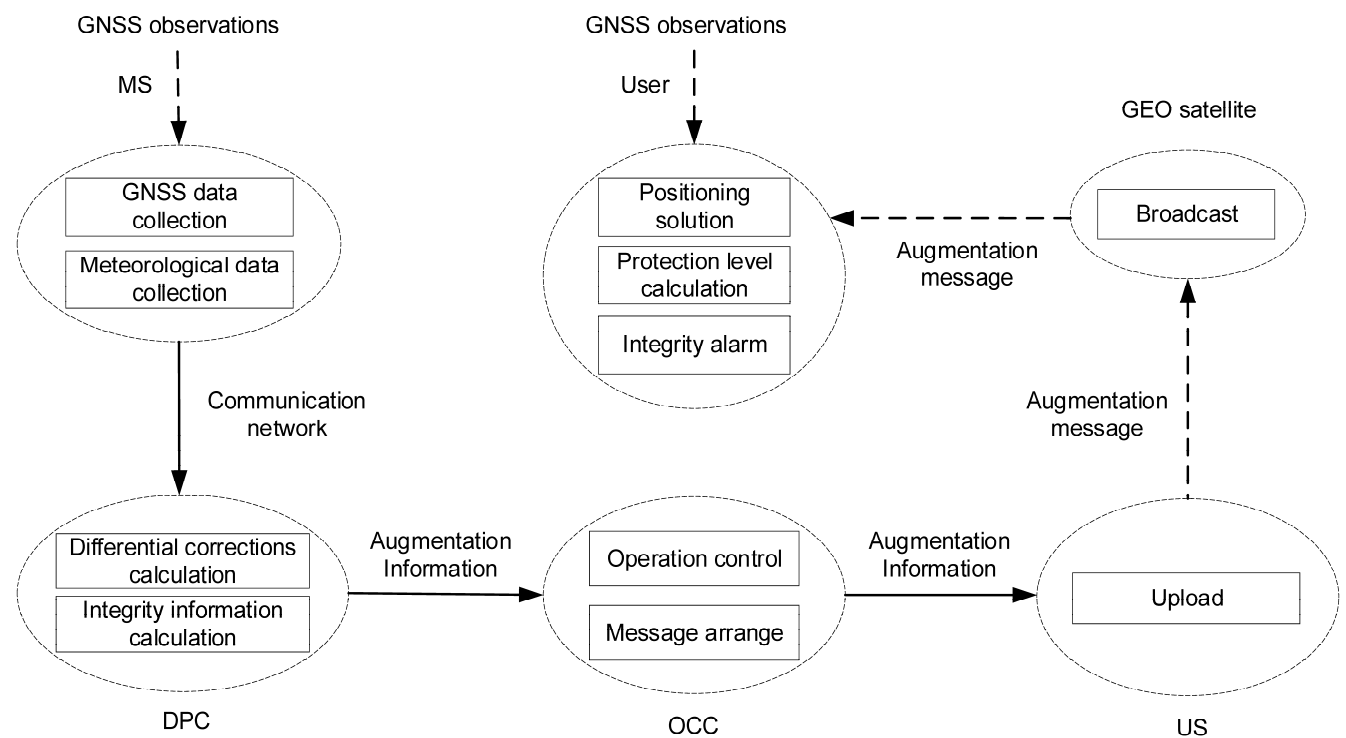

Figure 3. BDSBAS workflow.

\subsection{BDSBAS SF Solution}

The BDSBAS SF service guarantees the integrity of user positioning by broadcasting the satellite orbit, clock and ionospheric grid corrections, as well as the user differential range error (UDRE) and covariance information [33,34], as shown in Figure 4. After the positioning solution and the protection level calculation, the service performance can be further evaluated and analyzed.

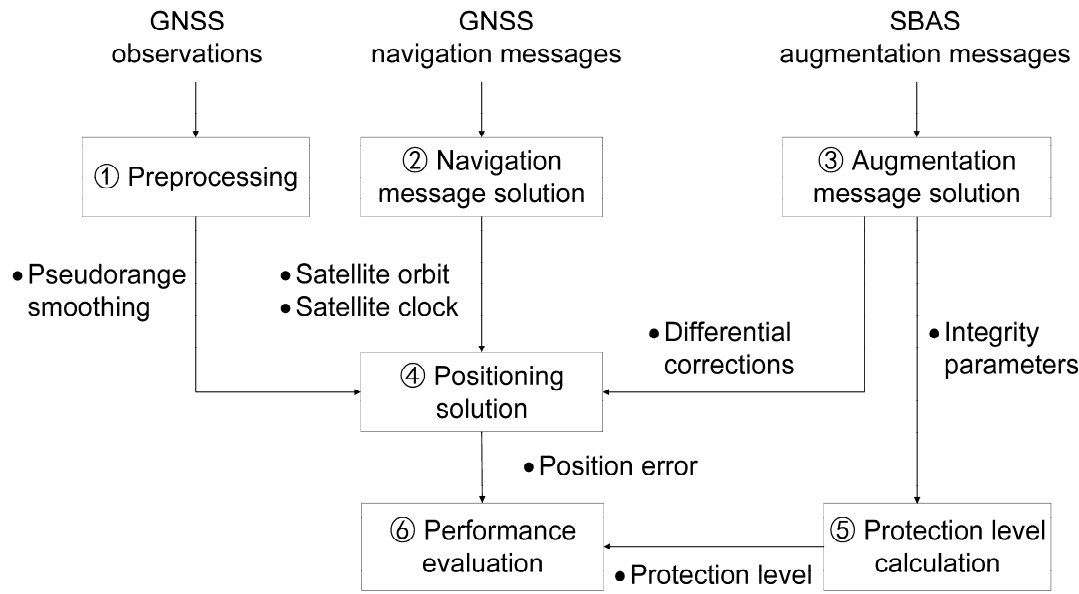

Figure 4. BDSBAS SF solution flow.

\subsubsection{Long-Term Correction and Fast Correction Calculation}

Limited by the data broadcast rate of SBAS satellites, the ephemeris corrections can be divided into long-term corrections and fast corrections. Among them, the long-term corrections are used to describe the slow change part of the satellite orbit and clock, and the broadcast period is $120 \mathrm{~s}$; the fast corrections are used to describe the fast change part of the satellite clock, and the broadcast period is $6 \mathrm{~s}$ (Cao et al., 2012).

\section{Long-Term Correction}

The BDSBAS SF long-term corrections are broadcast by the augmentation message type 25 (MT25), including the long-term corrections of satellite clock and the long-term corrections of satellite orbit, which are used to separately correct the GPS satellite clock and orbit. 
The satellite clock long-term correction $\delta \Delta t_{S V}(t)$ at the current observation time $t$ is calculated by:

$$
\delta \Delta t_{S V}(t)=\delta a_{f 0}+\delta a_{f 1}\left(t-t_{0}\right)
$$

where $\delta a_{f 0}$ is the satellite clock deviation. $\delta a_{f 1}$ is the satellite clock deviation rate. $t_{0}$ is the reference time of the corrections. After that, the corrected satellite clock error $B_{i}$ can be obtained as follows:

$$
B_{i}=c\left(\Delta t_{i}^{(s)}+\delta \Delta t_{S V, i}\right)
$$

where index $i$ refers to the $i$-th satellite. $\Delta t_{i}^{(s)}$ is the satellite clock error before correction. $c$ is the speed of light.

The satellite orbit correction $\left[\begin{array}{lll}\delta x_{k}(t) & \delta y_{k}(t) & \delta z_{k}(t)\end{array}\right]^{\mathrm{T}}$ is calculated by:

$$
\left[\begin{array}{l}
\delta x_{k}(t) \\
\delta y_{k}(t) \\
\delta z_{k}(t)
\end{array}\right]=\left[\begin{array}{c}
\delta x \\
\delta y \\
\delta z
\end{array}\right]+\left[\begin{array}{c}
\delta \dot{x} \\
\delta \dot{y} \\
\delta \dot{z}
\end{array}\right]\left(t-t_{0}\right)
$$

where $\left[\begin{array}{lll}\delta x & \delta y & \delta z\end{array}\right]^{\mathrm{T}}$ is the satellite orbit deviation. $\left[\begin{array}{lll}\delta \dot{x} & \delta \dot{y} & \delta \dot{z}\end{array}\right]^{\mathrm{T}}$ is the satellite orbit deviation rate. After that, the corrected satellite orbit coordinate $\left[\begin{array}{lll}\hat{x}_{k, i} & \hat{y}_{k, i} & \hat{z}_{k, i}\end{array}\right]^{\mathrm{T}}$ of satellite $i$ can be obtained as follows:

$$
\left\{\begin{array}{l}
\hat{x}_{k, i}=x_{k, i}+\delta x_{k, i} \\
\hat{y}_{k, i}=y_{k, i}+\delta y_{k, i} \\
\hat{z}_{k, i}=z_{k, i}+\delta z_{k, i}
\end{array}\right.
$$

where $\left[\begin{array}{lll}x_{k, i} & y_{k, i} & z_{k, i}\end{array}\right]^{\mathrm{T}}$ is the satellite orbit coordinate before correction. $\left[\begin{array}{lll}\delta x_{k, i} & \delta y_{k, i} & \delta z_{k, i}\end{array}\right]^{\mathrm{T}}$ is the satellite orbit correction.

\section{Fast Correction}

The BDSBAS SF fast corrections are currently broadcast by the augmentation message type 2-4 (MT2-4). Let $F C_{i \text {,current }}$ be the most recent fast correction that user received, and $F C_{i \text {,previous }}$ be a previous fast correction that user received. Then, the range rate correction (RRC) for satellite $i$ can be calculated by the fast corrections as follows:

$$
R R C_{i}=\frac{F C_{i, \text { current }}-F C_{i, \text { previous }}}{t_{i, 0 \mathrm{f}}-t_{i, 0 \mathrm{f} \_ \text {previous }}}
$$

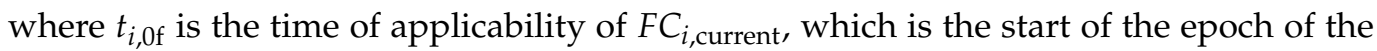
SBAS network time (SNT) second that is coincident with the transmission at the SBAS satellite of the first symbol of the message block. $t_{i, 0 f}$ previous is the time of applicability of $F C_{i \text {,previous. }}$

As a result, user's pseudo-range correction (PRC) for satellite $i$ can be further obtained by

$$
P R C_{i}=F C_{i, \text { previous }}+R R C_{i} \times\left(t-t_{i, 0 f}\right)
$$

where $t$ denotes the current calculation time of user.

\subsubsection{Atmospheric Delay Correction Calculation}

The atmospheric propagation delay of radio frequency (RF) signals is one of the main errors for GNSS. For the SF SBAS service, the tropospheric delay is corrected by using a dry-wet component model similar to that in GNSS, and the ionospheric delay is corrected by the broadcast corrections of the ionospheric grid points (IGP).

Ionospheric Correction

The ionospheric grid corrections of BDSBAS SF service are broadcast in the augmentation message type 26 (MT26). Since the system actually broadcasts the vertical delay 
corrections of the IGP, user needs to use the surrounding grid points to calculate the obliquity ionospheric delay corrections of its own pierce point.

Specifically, the user needs to first calculate the latitude $\phi_{p p}$ and longitude $\lambda_{p p}$ of the pierce point. Then, the ionospheric grid points around the pierce point are used to interpolate and obtain the vertical ionospheric delay estimate $\tau_{v p p}\left(\phi_{p p}, \lambda_{p p}\right)$ of the pierce point. At the same time, the residual variance $\sigma_{\mathrm{UIVE}}^{2}$ of the vertical ionospheric delay correction at the pierce point is obtained.

On this basis, the obliquity factor $F_{p p}$ is introduced and $\tau_{v p p}\left(\phi_{p p}, \lambda_{p p}\right)$ is further converted into the obliquity ionospheric delay correction $I C_{i}$ for user's final use, which can be expressed as follows:

$$
I C_{i}=-F_{p p} \cdot \tau_{v p p}\left(\phi_{p p}, \lambda_{p p}\right)
$$

with

$$
F_{p p}=\left[1-\left(\frac{R_{e} \cos E}{R_{e}+h_{l}}\right)^{2}\right]^{-\frac{1}{2}}
$$

where $E$ is the satellite elevation angle, $R_{e}=6378.1363 \mathrm{~km}$ is the radius of the earth, and $h_{l}=350 \mathrm{~km}$ is the height of the maximum electron density layer.

Finally, the obliquity factor $F_{p p}$ is used to update $\sigma_{\mathrm{UIVE}}^{2}$, and obtain the residual variance $\sigma_{\text {UIRE }}^{2}$ of the obliquity ionospheric delay for the pierce point, which can be expressed by

$$
\sigma_{\mathrm{UIRE}}^{2}=F_{p p}^{2} \cdot \sigma_{\mathrm{UIVE}}^{2}
$$

where the residual variance $\sigma_{\mathrm{UIRE}}^{2}$ will be used in the subsequent calculation of the protection level.

\section{Tropospheric Correction}

Use the tropospheric delay model to calculate the tropospheric correction $T C_{i}$, as shown in:

$$
T C_{i}=-\left(d_{\text {hyd }}+d_{\text {wet }}\right) \times m\left(E_{i}\right)
$$

with

$$
m\left(E_{i}\right)=\frac{1.001}{\sqrt{0.002001+\sin ^{2}\left(E_{i}\right)}}
$$

where $m\left(E l_{i}\right)$ is the mapping function of the tropospheric delay. $d_{h y d}$ and $d_{\text {wet }}$ denote the dry and wet components of the troposphere, respectively, which are jointly calculated by the meteorological parameters such as air pressure, temperature, temperature change rate, water vapor pressure, and water vapor pressure change rate.

At last, similar to the calculation of the ionospheric correction, the residual $\sigma_{i, \text { tropo }}$ of the corrected tropospheric delay must be estimated at the same time to calculate the protection level (PL), as shown in:

$$
\sigma_{i, \text { tropo }}=\sigma_{T V E} \times m\left(E l_{i}\right)
$$

where $\sigma_{T V E}$ represents the vertical tropospheric delay error, which can generally be taken as $0.12 \mathrm{~m}$.

\subsubsection{Degradation Parameter Calculation}

The degradation parameter characterizes the degree to which the correction effect decreases due to the delay between the current time $t$ when the user uses the correction and the reference time $t_{0}$ of the correction, and it is the basis for the PL calculation. It mainly includes the user differential range estimate (UDRE) degradation factor $\delta \mathrm{UDRE}$, the fast correction degradation factor $\varepsilon_{f c}$, the long-term correction degradation factor $\varepsilon_{l t c}$, the distance changing correction degradation factor $\varepsilon_{r r c}$, and the application mode degradation 
factor $\varepsilon_{e r}$. For the complete and detailed calculation process, please refer to RTCA DO-229 (RTCA 2016).

After obtaining the various degradation factors, the residual variance $\sigma_{f l t}^{2}$ of user measurement after error correction can be further calculated as follows:

$$
\sigma_{f l t}^{2}= \begin{cases}\left(\sigma_{\mathrm{UDRE}} \cdot \delta \mathrm{UDRE}+\varepsilon_{f c}+\varepsilon_{r r c}+\varepsilon_{l t c}+\varepsilon_{e r}\right)^{2}, & \text { if } R S S_{\mathrm{UDRE}}=0 \\ \left(\sigma_{\mathrm{UDRE}} \cdot \delta \mathrm{UDRE}\right)^{2}+\varepsilon_{f c}^{2}+\varepsilon_{r r c}^{2}+\varepsilon_{l t c}^{2}+\varepsilon_{e r}^{2}, & \text { if } R S S_{\mathrm{UDRE}}=1\end{cases}
$$

where $\sigma_{U D R E}$ is converted from the UDRE, and the two have the following exact relationship:

$$
\mathrm{UDRE}=3.29 \sigma_{\mathrm{UDRE}}
$$

and the UDRE parameters are broadcast in the SBAS augmentation MTs 2, 3, 4, 5, and 6 in the form of the user differential range estimate indicators (UDREI).

\subsubsection{Protection Level Calculation}

Before the protection level calculation, user needs to first calculate the noise variance $\sigma_{i}^{2}$ of the pseudo-range observation value between himself and satellite $i$, which can be expressed as follows:

$$
\sigma_{i}^{2}=\sigma_{i, f l t}^{2}+\sigma_{i, \mathrm{UIRE}}^{2}+\sigma_{i, a i r}^{2}+\sigma_{i, \text { tropo }}^{2}
$$

with

$$
\sigma_{i, a i r}^{2}=\left(0.0741+0.18 e^{\left(E_{i} / 27.7^{\circ}\right)}\right)^{2}
$$

where $\sigma_{i, a i r}^{2}$ is the multipath and receiver thermal noise, and the calculation of $\sigma_{i, f l t}^{2}, \sigma_{i, \mathrm{UIRE}}^{2}$ and $\sigma_{i, \text { tropo }}^{2}$ have already been described in above.

Thus, the weight matrix $W$ can be constructed as follows:

$$
W_{i i}=\sigma_{i}^{-2}
$$

where $W_{i i}$ denotes the $i$-th diagonal element of $W$.

On this basis, the weighted covariance matrix can be obtained by using matrices $G$ and $W$ as follows:

$$
\left(G^{T} W G\right)^{-1}=\left[\begin{array}{cccc}
d_{E}^{2} & d_{E N} & d_{E U} & d_{E T} \\
d_{E N} & d_{N}^{2} & d_{N U} & d_{N T} \\
d_{E U} & d_{N U} & d_{U}^{2} & d_{U T} \\
d_{E T} & d_{N T} & d_{U T} & d_{T}^{2}
\end{array}\right]
$$

where indices $E, N$, and $U$ refer to the east, north and up directions of the user receiver, respectively, and $T$ refer to the receiver clock.

Therefore, the horizontal protection level (HPL) and the vertical protection level (VPL) can be calculated as follows:

$$
\begin{gathered}
\mathrm{HPL}=\left\{\begin{array}{c}
K_{\mathrm{H}, \mathrm{NPA}} \cdot d_{\text {major }} \mathrm{En}-\text { route to LNAV } \\
K_{\mathrm{H}, \mathrm{PA}} \cdot d_{\text {major }} \mathrm{LNAV} / \mathrm{VNAV}, \mathrm{LP}, \mathrm{LPV}
\end{array}\right. \\
\mathrm{VPL}=K_{V} d_{U}
\end{gathered}
$$

With

$$
d_{\text {major }}=\sqrt{\frac{d_{E}^{2}+d_{N}^{2}}{2}+\sqrt{\left(\frac{d_{E}^{2}-d_{N}^{2}}{2}\right)^{2}+d_{E N}^{2}}}
$$

where $K_{H, N P A}=6.18 \mathrm{~m}, K_{H, P A}=6.0 \mathrm{~m}$, and $K_{V}=5.33 \mathrm{~m}$. 


\subsubsection{Carrier Smoothing Pseudo-Range}

In order to reduce the code measurement noise and improve the ranging accuracy, the DO-229E standard recommends, the following $\alpha-\beta$ filter is used to smooth the raw pseudo-range observations:

$$
\left\{\begin{array}{c}
P_{n}=\alpha \rho_{n}+(1-\alpha) P_{\text {proj }} \\
P_{\text {proj }}=P_{n-1}+\frac{\lambda}{2 \pi}\left(\varphi_{n}-\varphi_{n-1}\right)
\end{array}\right.
$$

where $P_{n}$ and $P_{n-1}$ are the smoothed pseudo-ranges of the current epoch $n$ and the previous epoch $n-1$, respectively. $P_{\text {proj }}$ is the projected pseudo-range; $\varphi_{n}$ and $\varphi_{n-1}$ are the accumulated carrier phase measurements of the current epoch $n$ and the previous epoch $n-1$, respectively. $\lambda$ is the wavelength. $\rho_{n}$ is the raw pseudo-range measurement. $\alpha$ is the weight parameter in the filter $(\alpha<1)$.

Using the smoothed pseudo-range $P_{n}$, the final corrected pseudo-range $\hat{P}_{n}$ for user position calculation can be further obtained by:

$$
\hat{P}_{n, i}=P_{n, i}+P R C_{i}+B_{i}-I C_{i}-T C_{i}
$$

where the positive and negative signs of different corrections should be paid attention to.

\section{BDSBAS Service Performance Evaluation}

BDSBAS service performance is described by four types of indicators: positioning accuracy, continuity, availability, and integrity. Combined with the known location reference benchmarks, the system service performance can be evaluated.

\subsection{Positioning Accuracy}

The positioning accuracy of SBAS is usually measured from both horizontal and vertical directions, and it is defined as the $95 \%$ quantile of the positioning error within a period of time when the protection level is less than the alarm limit, which can be expressed as follows:

$$
\left\{\begin{array}{l}
\mathrm{P}(|\mathrm{HPE}|<\operatorname{HPA}(|95 \%|))=95 \% \\
\mathrm{P}(|\mathrm{VPE}|<\operatorname{VPA}(|95 \%|))=95 \%
\end{array}\right.
$$

where HPE and VPE denotes the horizontal positioning error and the vertical positioning error, respectively, and HPA and VPA denotes the horizontal positioning accuracy and the vertical positioning accuracy, respectively.

\subsection{Availability}

Availability is defined as the percentage of the number of samples whose PL is less than the alarm limit (AL) within a period of time to the total number of samples, as shown in Figure 5. For the horizontal and vertical directions, the above conditions must be met (that is, HPL $<$ HAL, VPL $<$ VAL).

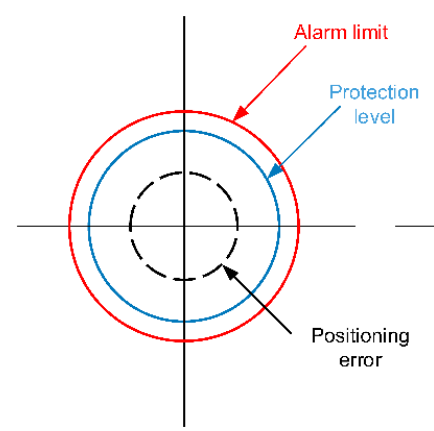

Available

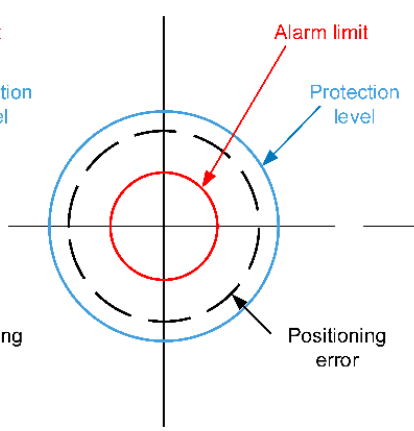

Unavailable

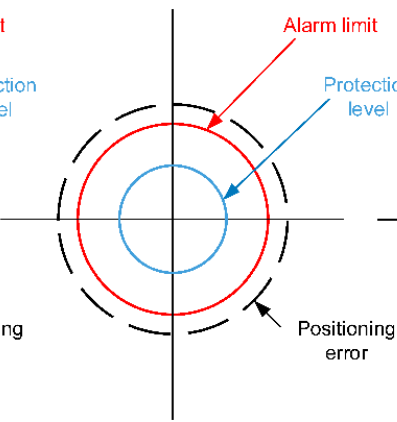

Available (Missing alarm)

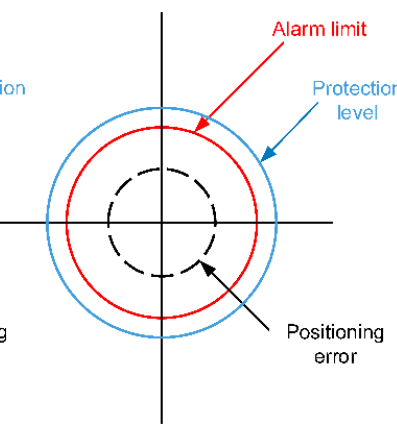

Unavailable (False alarm)

Figure 5. Concept of service availability. 
When judging whether the service of each epoch is available, there may be several different situations:

- The positioning error (PE) is less than the protection level, and the PL is less than the AL. Therefore the service is available;

- The PE is less than the AL, and the AL is less than the PL. The service is unavailable;

- The PL is less than the AL, and the AL is less than the PE. In this case, the service will be misjudged as available, causing system miss alarms and result in serious integrity risk events;

- The PE is less than the AL, and the AL is less than the PL. In this case, the service will be misjudged as unavailable, causing system false alarms and affecting the availability and continuity of the service.

\subsection{Continuity}

The following relationship exists between continuity risk and continuity:

$$
\text { Continuity }=1-\text { Continuity risk }
$$

where continuity risk is defined as the ratio of the number of continuity events to the total number of samples obtained using a 15 s sliding window for a period of time, as shown in Figure 6. A continuity event will cause the system which was originally available to become unavailable within the next $15 \mathrm{~s}$.

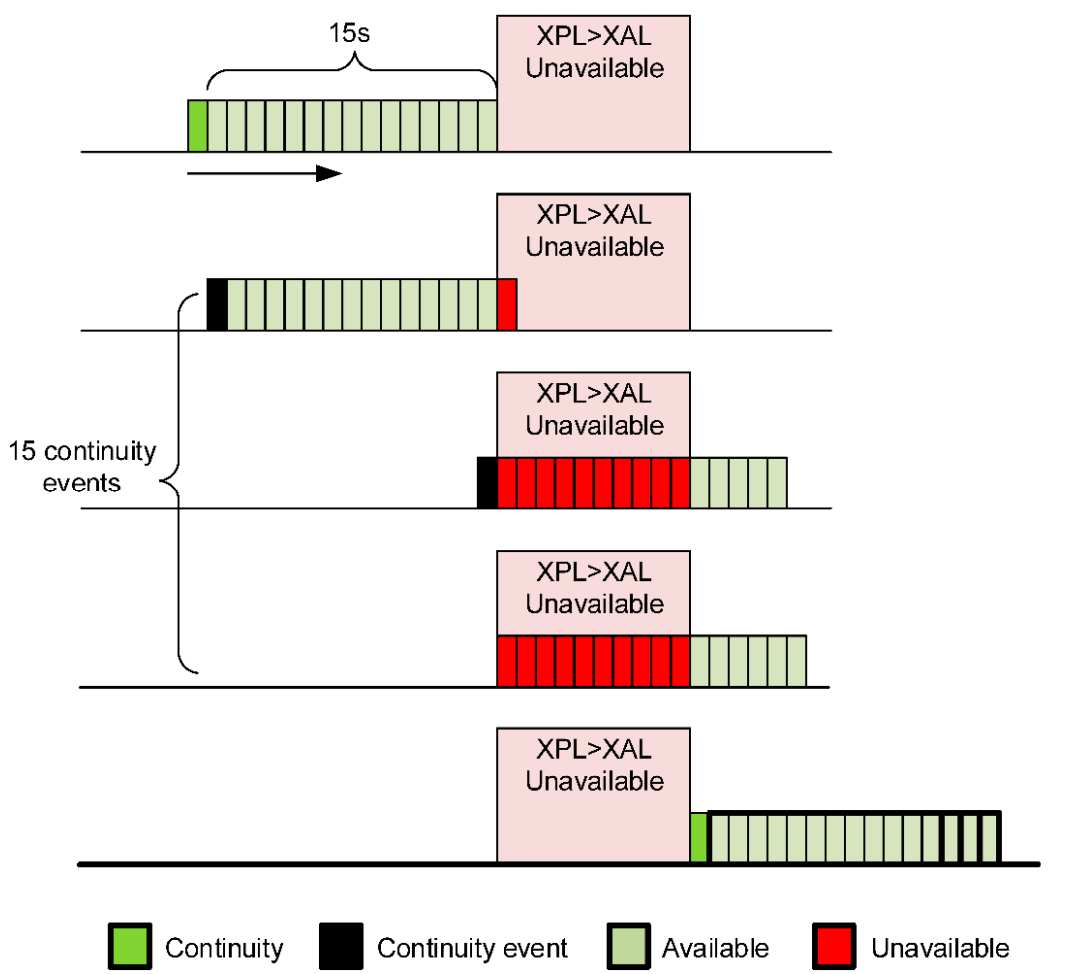

Figure 6. Using a $15 \mathrm{~s}$ sliding window to assess continuity risk. For a specific epoch, if the system is available at the beginning, and becomes unavailable for at least one second in the next $15 \mathrm{~s}$ (for example, the signal is lost for more than four seconds or the protection level exceeds the alarm threshold), then a continuity event occurs. If a service is unavailable within a second, this will result in 15 continuity events.

\subsection{Integrity}

An integrity event is defined as an event where the PE is greater than or equal to the corresponding service PL (as shown in Figure 7). 


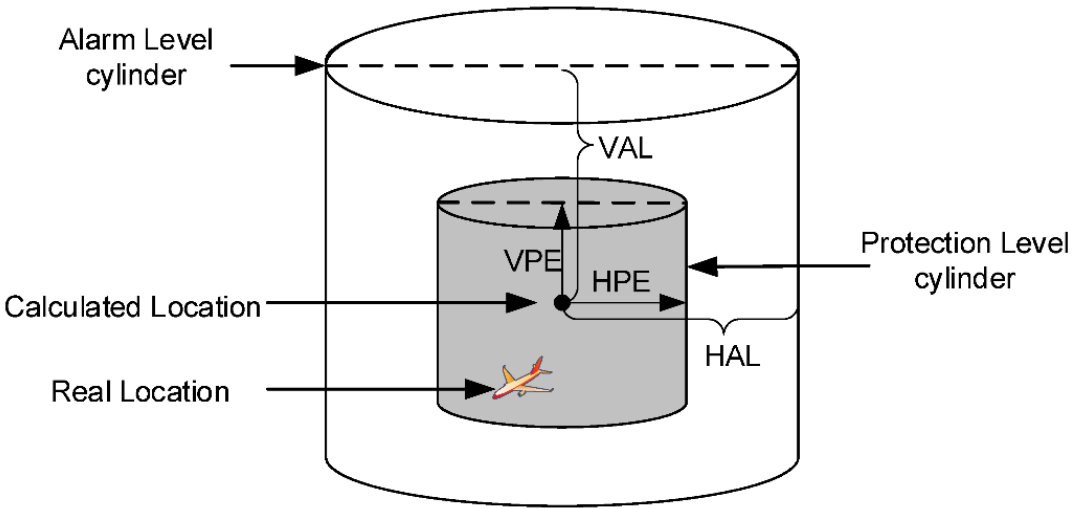

Figure 7. We used the cylinders to explain the status of the system service. When the protection level cylinder is inside the alarm level cylinder, the service is available. Otherwise, the service is unavailable. When the position error is within the protection level cylinder, missing alarms and integrity events will not occur in the service. Otherwise, missing alarms and integrity events may occur.

Generally, the safety index can be used to describe the degree of coverage of the PL to the PE [35]:

$$
\text { Safety index }=\text { PL/PE }
$$

which indicates that if the PL can 100\% cover the PE during the evaluation period, the safety index of each epoch will be greater than 1 . At this point, this means that the system can correctly determine the availability of the service, no alarms will be missed, and no integrity events will occur. In addition to the safety index, the Stanford triangle diagram is often used internationally to represent the integrity of the service.

\section{BDSBAS Aviation Flight Test}

As with other SBASs, BDSBAS must be certified by the civil aviation department in order to serve civil aviation users. Therefore, an aviation flight test is one of the necessary tasks to verify the SF service performance of BDSBAS meeting the APV-I requirements (the HAL and VAL of which are $40 \mathrm{~m}$ and $50 \mathrm{~m}$, respectively). General aviation aircraft have characteristics such as low cost and high flexibility. Using them to carry out BDSBAS preliminary service performance testing can provide experience and reference for subsequent cooperation with the civil aviation department to carry out formal testing and airworthiness certification.

\subsection{Flight Test Environment}

The aviation flight test was carried out at Caihu Airport in Faku County, Shenyang City, Liaoning Province from 17 to 25 September 2020, and the take-off and landing operations during the approach phase and the transition flight operations during the airway flight phase of civil aviation aircraft were simulated. A small general aviation aircraft was used and a Septentrio PolaRx5 receiver was equipped with to verify the performance of the BDSBAS SF augmentation service. The tests results in this paper were performed in postprocessing. In order to obtain the aircraft trajectory reference, an RTK system was built using two Novartis receivers. One was set up near the airport as a reference station, and the other was used as a rover station, sharing the aerial antenna mounted on the aircraft with the Septentrio PolaRx 5 receiver with $1 \mathrm{~Hz}$ sampling rate and cut-off elevation angle of 10 degree. The aircraft reference trajectory of flight test I and test II were obtained by post-RTK using GPS dual-frequency observation data; the fixed rate reached $100 \%$ and the position accuracy was better than $5 \mathrm{~cm}$; the aircraft reference trajectory of flight test III was obtained by float-PPP using GPS dual-frequency observation data. The position accuracy is better than $10 \mathrm{~cm}$. 
The above-mentioned aviation flight test environment and equipment are shown in Figure 8 .
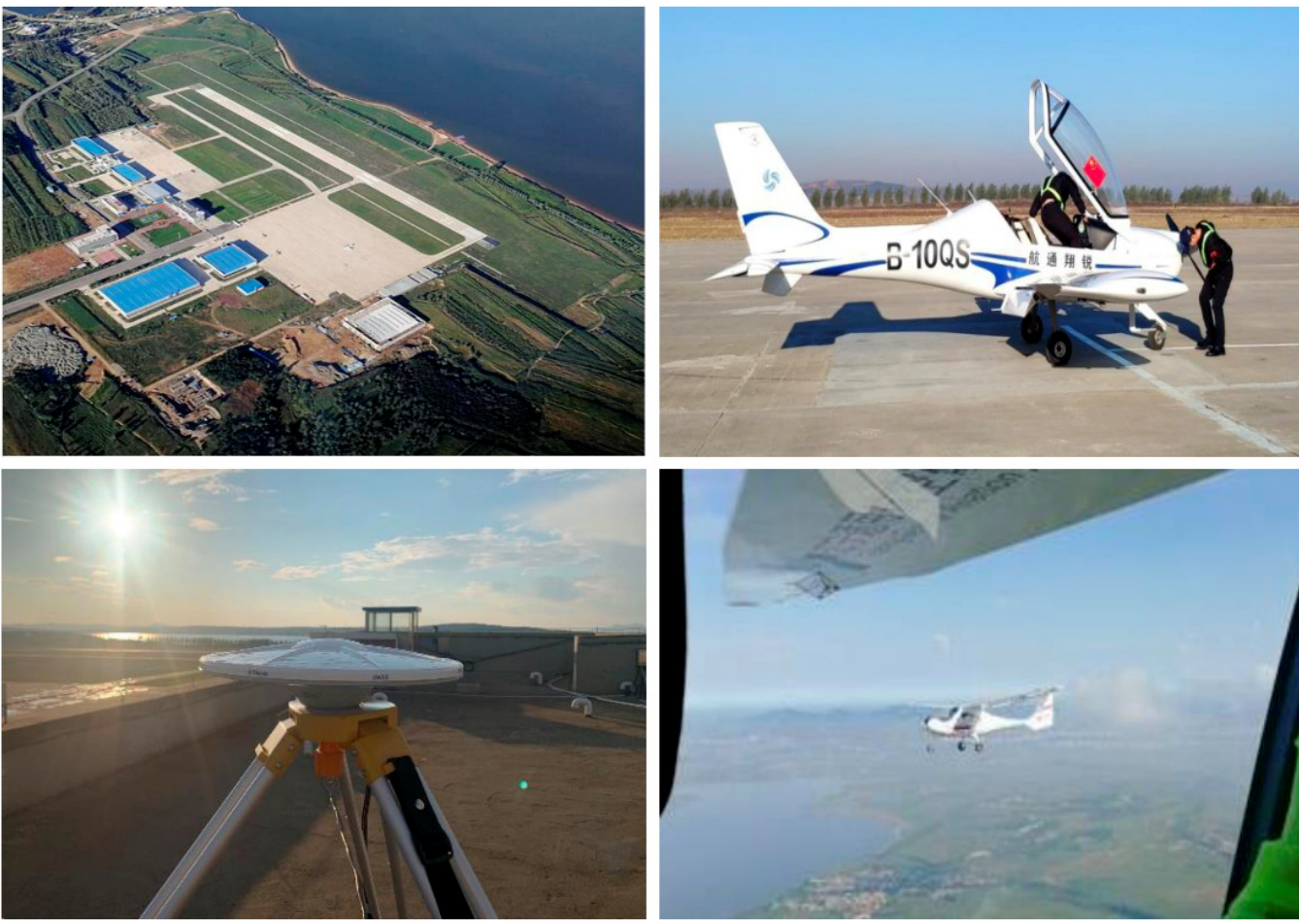

Figure 8. The figure presents the flight test environment. The top left panel is the aerial view of Shenyang Caihu Airport. The top right panel is the B-10QS general aviation aircraft which was used in the test. The bottom left panel is the RTK reference station installed at the airport. The bottom right panel is a photo of the B-10QS aircraft taken by another companion aircraft during the flight.

\subsection{Flight Test-I}

On 17 September 2020, the take-off and landing operation test was conducted to simulate the flight status of civil aviation aircraft during the approach phase. The flight lasts $2 \mathrm{~h}$ and $40 \mathrm{~min}$, and the trajectory is shown in Figure 9.

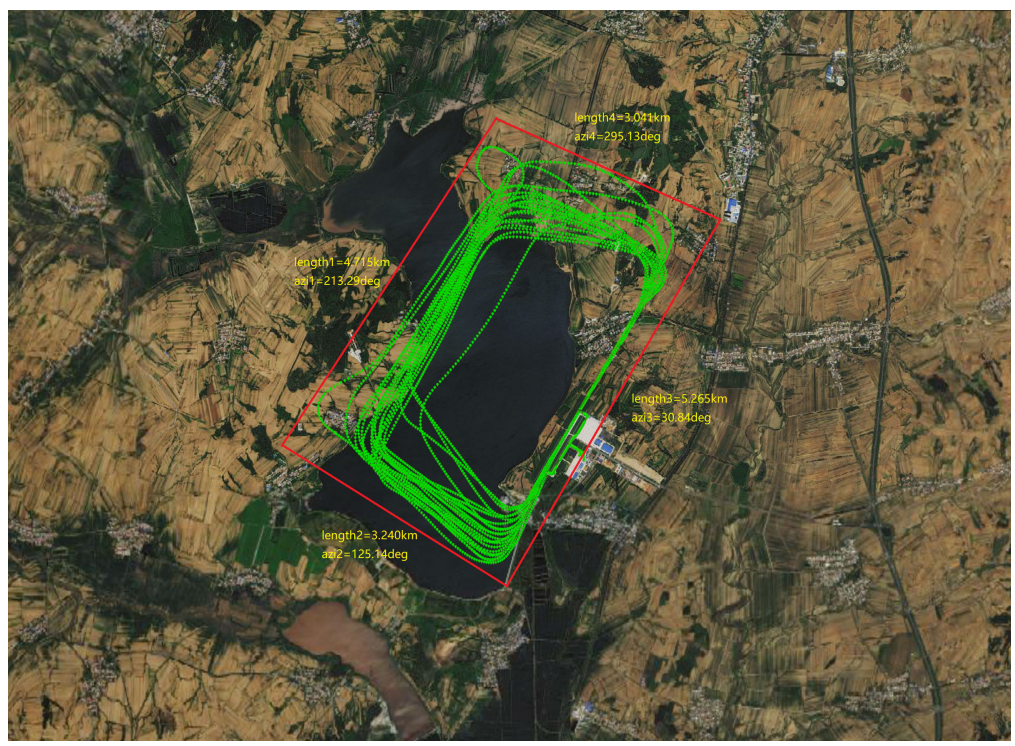

Figure 9. Flight trajectory of test-I. The green line is the trajectory, while the flight distance and azimuth are marked by the red line and the yellow text. 
The SF augmentation message broadcast by BDSBAS-B1C signal is used for the protection level (PL) calculation and position solution of the aircraft, and the RTK output is used as the reference to obtain the PE. The histogram of HPE and VPE are shown in Figures 10 and 11, respectively. The PE and the PL sequences are shown in Figure 12. On this basis, the horizontal and vertical Stanford triangle charts are generated, as shown in Figure 13.

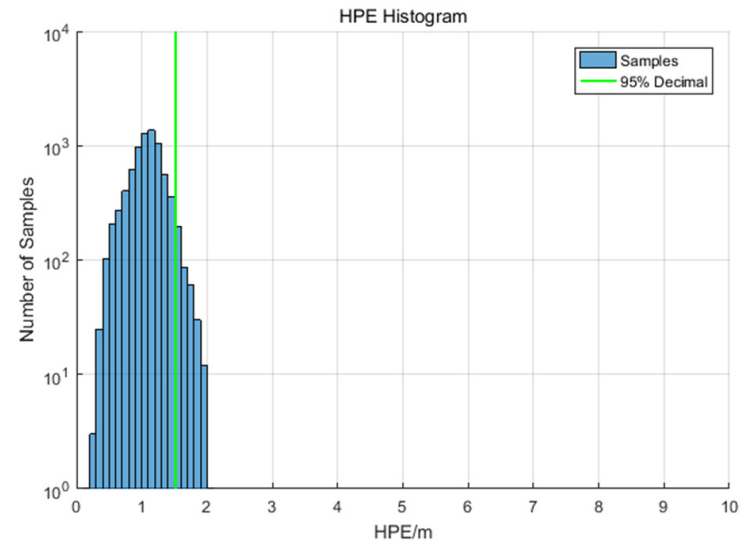

Figure 10. The HPE histogram of flight test-I. The green line in the figure is the horizontal accuracy $(95 \%)$, which is $1.62 \mathrm{~m}$.

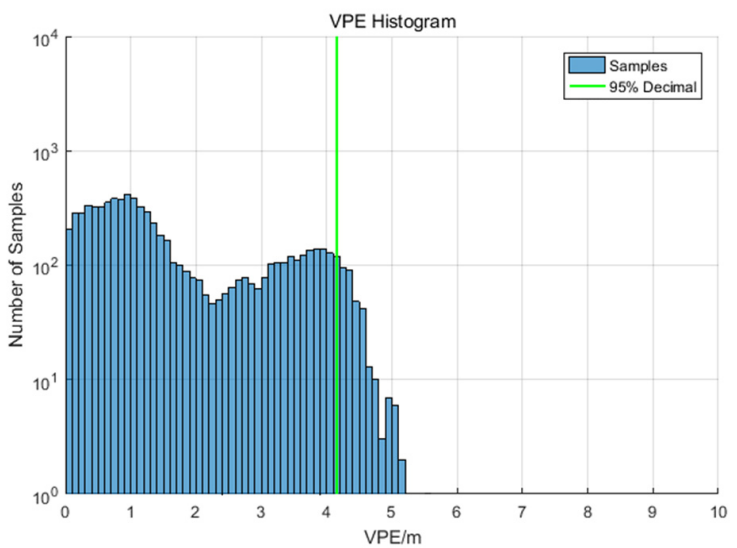

Figure 11. The VPE histogram of flight test-I. The green line in the figure is the vertical accuracy $(95 \%)$, which is $4.38 \mathrm{~m}$.
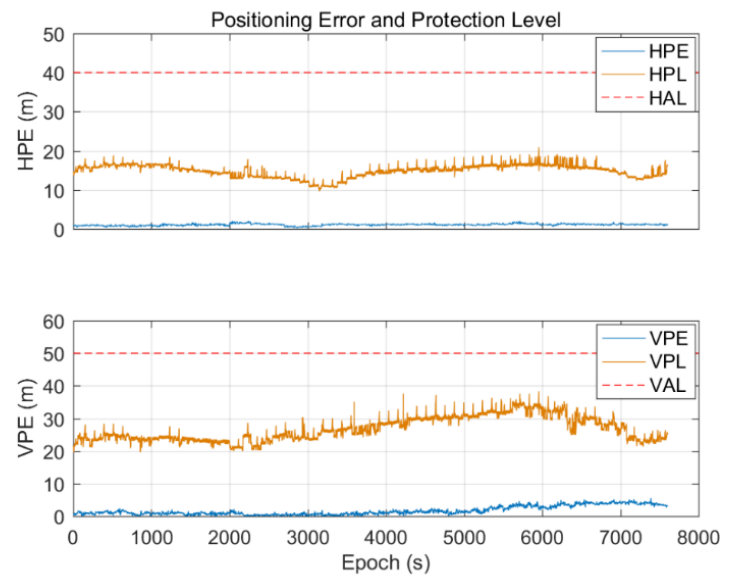

Figure 12. The PE, PL, and AL sequences of flight test-I. In both the horizontal direction (see the top panel) and the vertical direction (see the bottom panel), the PL can completely cover the PE and neither exceeds the PL, which means that no false alarms or missed alarms occurred during the test. 

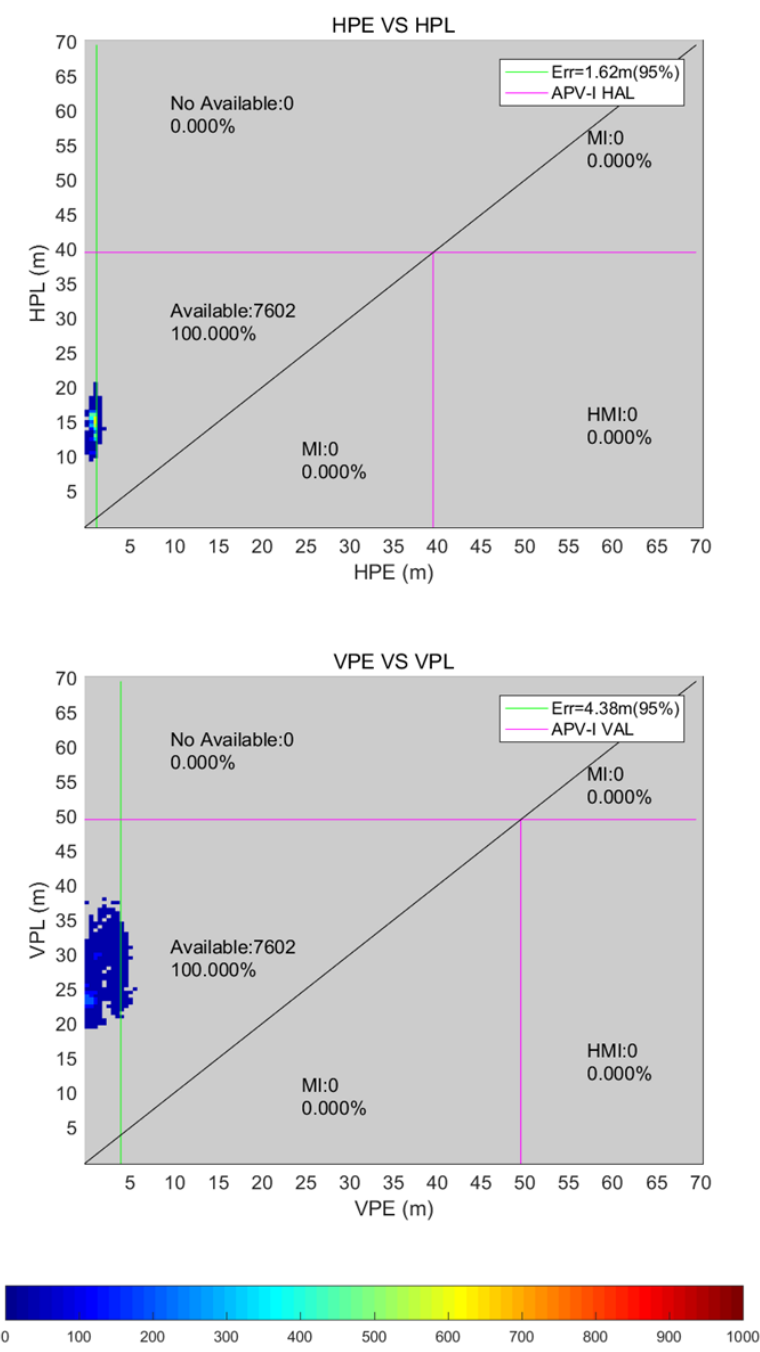

Figure 13. Stanford triangle charts for flight test-I. The top panel and the bottom panel are the horizontal Stanford chart and the vertical Stanford chart, respectively.

Table 2 shows the statistics of the performance indicators. It can be seen from Figures 12 and 13, and Table 2 that for the flight test-I conducted on 17 September 2020, the BDSABS SF augmentation positioning accuracy meets the requirements of the civil aviation APV-I accuracy index, and the PL can completely cover the PE. No integrity risk events occurred during the test, and the availability and continuity of the service reached $100 \%$.

Table 2. BDSBAS SF performance statistics of flight test-I.

\begin{tabular}{cc}
\hline Indicators & Statistical Results \\
\hline Horizontal accuracy/m (95\%) & 1.62 \\
Vertical accuracy / m (95\%) & 4.38 \\
Minimum horizontal safety index & 7.160 \\
Minimum vertical safety index & 4.594 \\
NPA availability & $100.00 \%$ \\
NPA continuity & $100.00 \%$ \\
NPA HMI events & 0 \\
APV-I availability & $100.00 \%$ \\
APV-I continuity & $100.00 \%$ \\
APV-I HMI events & 0 \\
\hline
\end{tabular}




\subsection{Flight Test-II}

On 18 September 2020, the take-off and landing operation test and the great-circle flight operation test were constructed in a circular airspace with a radius of $10 \mathrm{~km}$ above the airport in order to simulate the flight status of civil aviation aircraft during the approach phase. The flight lasted $2 \mathrm{~h}$ and $15 \mathrm{~min}$, and the trajectory is shown in Figure 14.

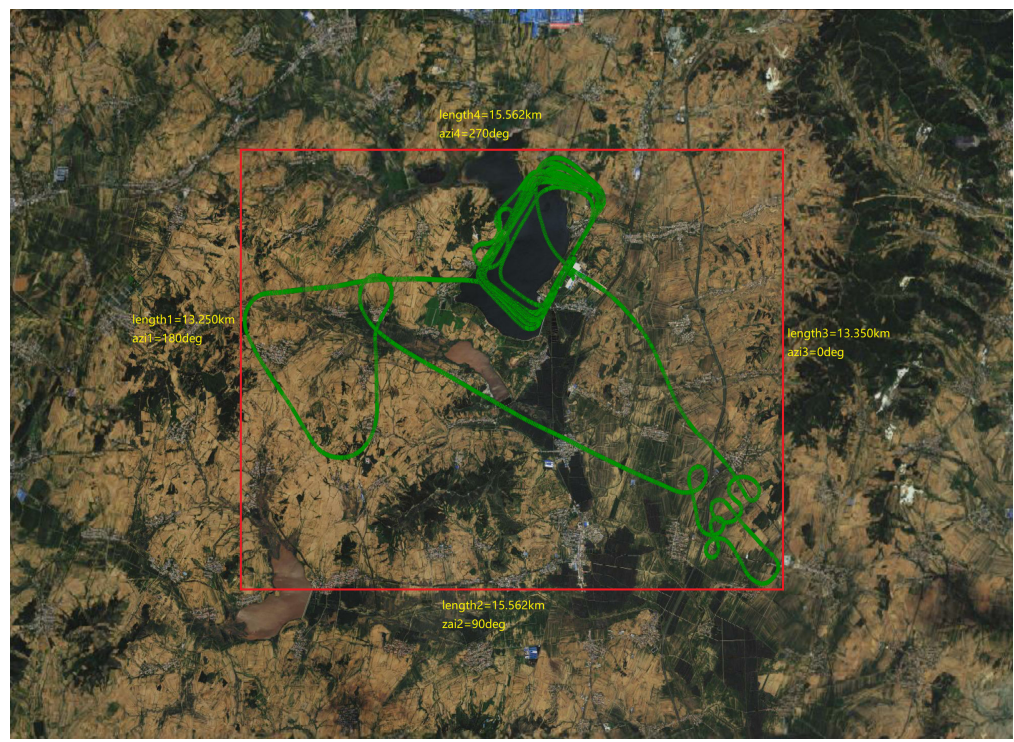

Figure 14. Flight trajectory of test-II. The green line is the trajectory, while the flight distance and azimuth are marked by the red line and the yellow text.

Similarly, the PL can be calculated by the SF augmentation message and the RTK output is used as the reference to obtain the PE. The histogram of HPE and VPE are shown in Figures 15 and 16, respectively. The PE and the PL sequences are shown in Figure 17, and the horizontal and vertical Stanford triangle charts are shown in Figure 18.

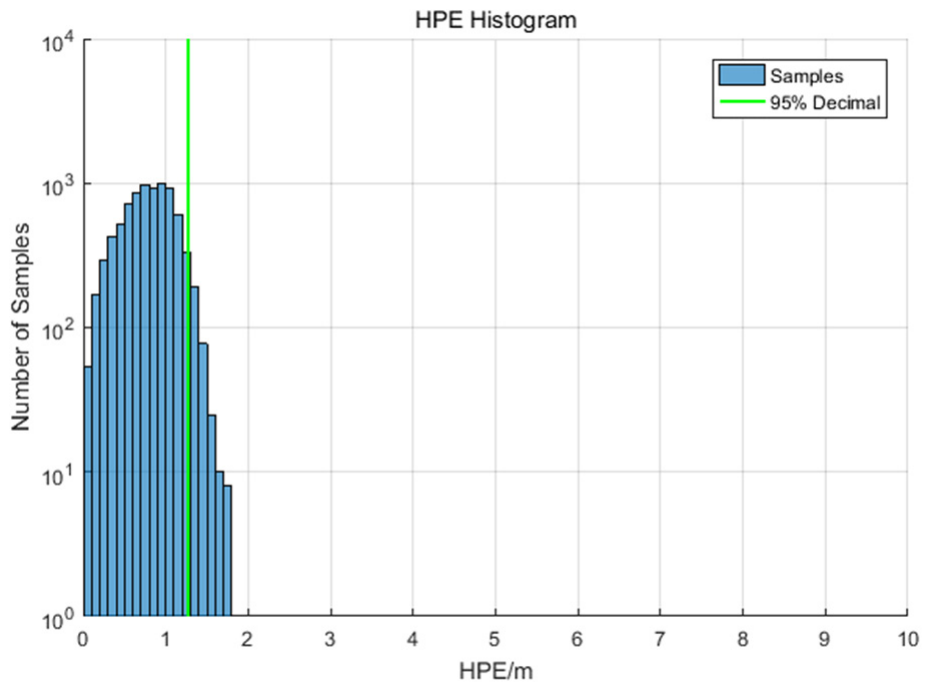

Figure 15. The HPE histogram of flight test-II. The green line in the figure is the horizontal accuracy (95\%), which is $1.27 \mathrm{~m}$. 


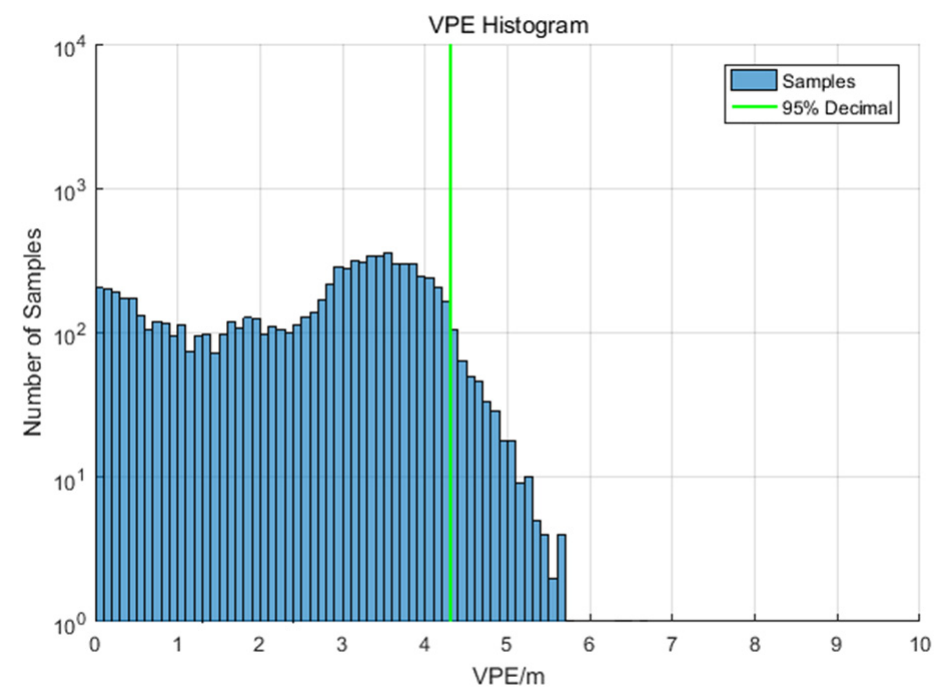

Figure 16. The VPE histogram of flight test-II. The green line in the figure is the vertical accuracy (95\%), which is $4.30 \mathrm{~m}$.
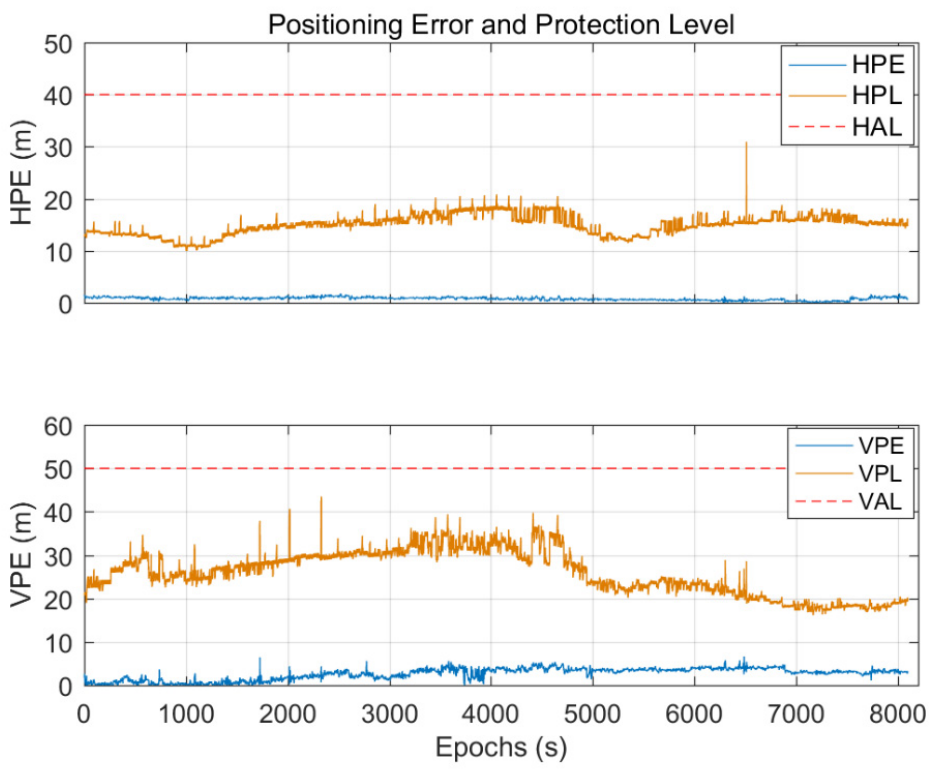

Figure 17. The PE, PL, and AL sequences of flight test-II. In both the horizontal direction (see the top panel) and the vertical direction (see the bottom panel), the PL can completely cover the PE and neither exceeds the PL, which means that no false alarms or missed alarms occurred during the test.

Table 3 shows the statistics of the performance indicators. It can be seen from Figures 17 and 18, and Table 3 that for the flight test-II conducted on 18 September 2020, the BDSABS SF augmentation positioning accuracy meets the requirements of the civil aviation APV-I accuracy index, and the PL can completely cover the PE. No integrity risk events occurred during the test, and the availability and continuity of the service reached $100 \%$. 

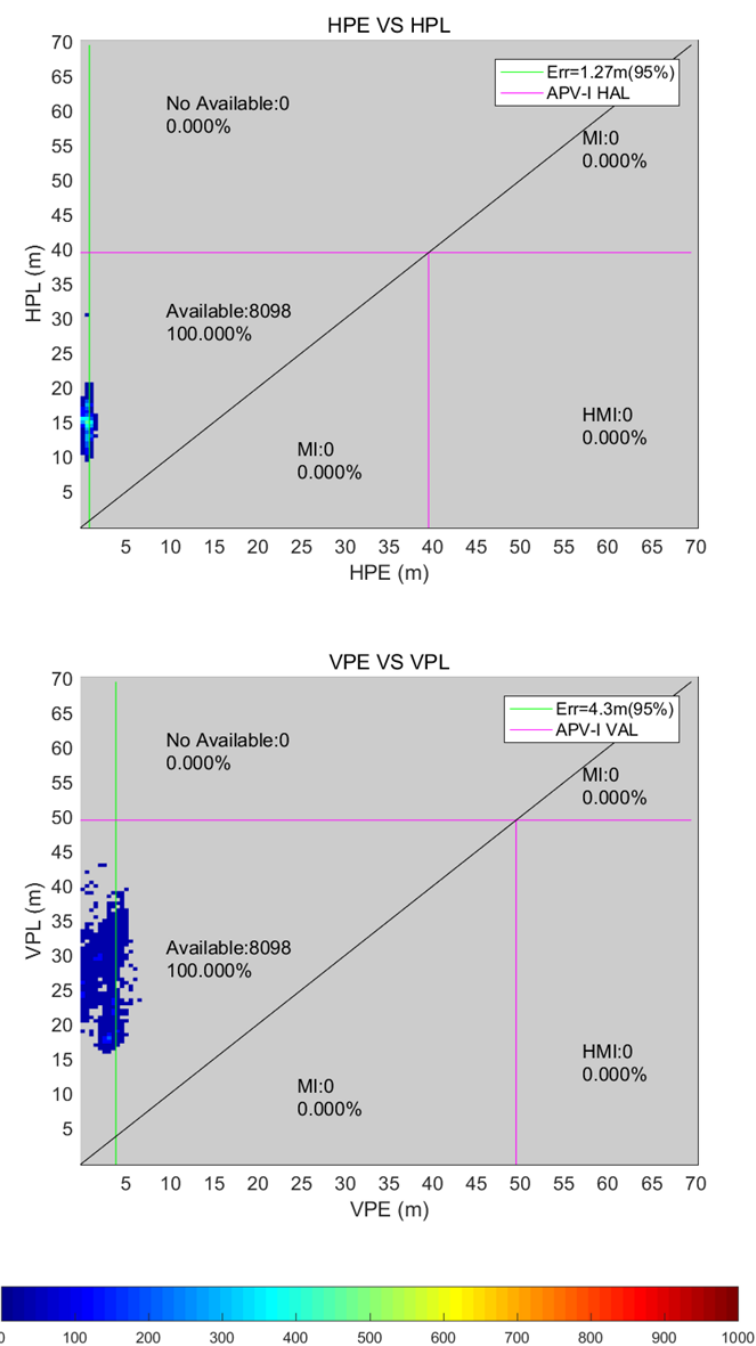

Figure 18. Stanford triangle charts for flight test-II. The top panel and the bottom panel are the horizontal Stanford chart and the vertical Stanford chart, respectively.

Table 3. BDSBAS SF performance statistics of flight test-II.

\begin{tabular}{cc}
\hline Indicators & Statistical Results \\
\hline Horizontal accuracy /m (95\%) & 1.27 \\
Vertical accuracy/m (95\%) & 4.30 \\
Minimum horizontal safety index & 8.860 \\
Minimum vertical safety index & 2.582 \\
NPA availability & $100.00 \%$ \\
NPA continuity & $100.00 \%$ \\
NPA HMI events & 0 \\
APV-I availability & $100.00 \%$ \\
APV-I continuity & $100.00 \%$ \\
APV-I HMI events & 0 \\
\hline
\end{tabular}

\subsection{Flight Test-III}

The transition flight test was carried out on 25 September 2020. The plane took off from Caihu Airport and flew for about $180 \mathrm{~km}$ to the southwest before flying for about $180 \mathrm{~km}$ to the southeast to arrive at the second airport. It did not land at the second airport, but returned to Caihu Airport on the same route for great-circle flights before landing. The flight lasted $3 \mathrm{~h}$ and $55 \mathrm{~min}$, and the trajectory is shown in Figure 19. 


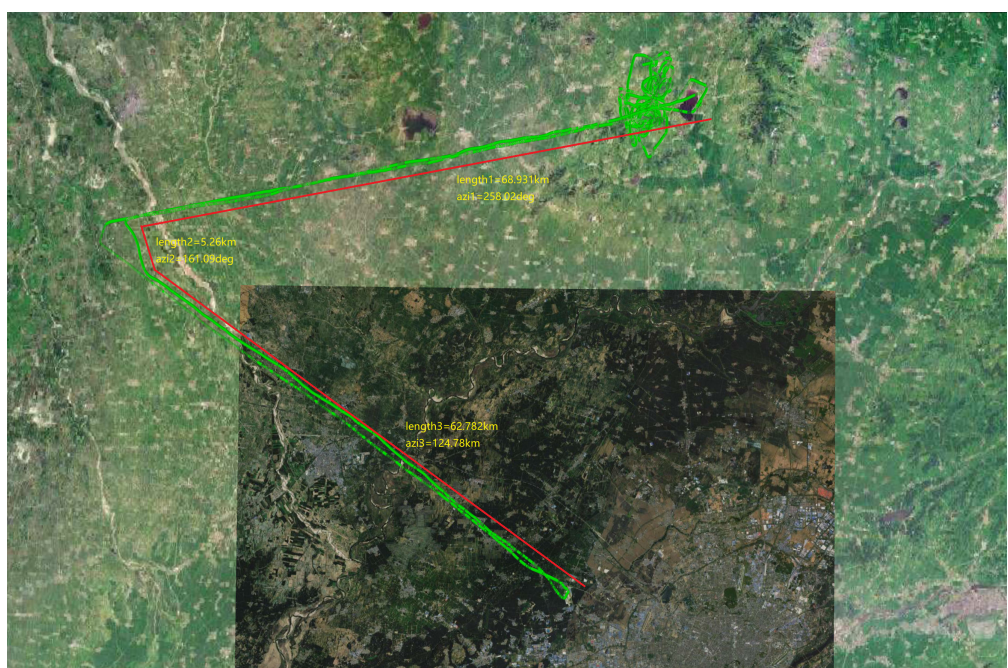

Figure 19. Flight trajectory of test-III. The green line is the trajectory, while the flight distance and azimuth are marked by the red line and the yellow text.

Similarly, the PL can be calculated by the SF augmentation message and the RTK output is used as the reference to obtain the PE. The the histogram of HPE and VPE are shown in Figures 20 and 21, respectively. The PE and the PL sequences are shown in Figure 22, and the horizontal and vertical Stanford triangle charts are shown in Figure 23.

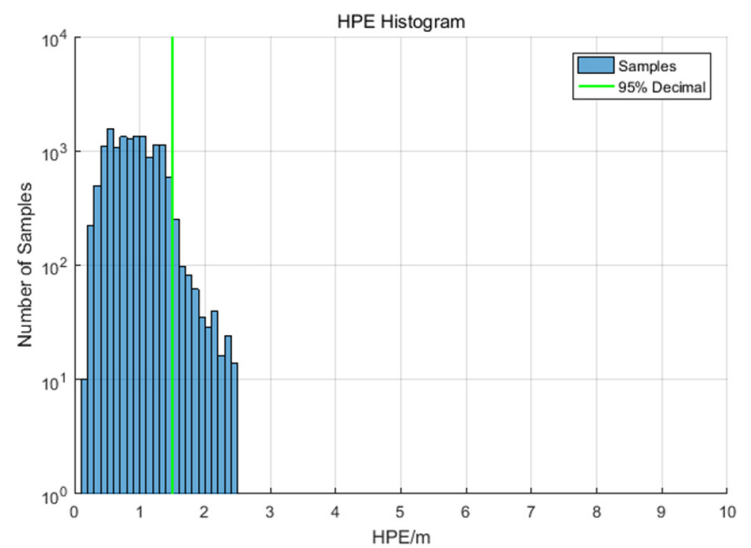

Figure 20. The HPE histogram of flight test-III. The green line in the figure is the horizontal accuracy $(95 \%)$, which is $1.49 \mathrm{~m}$.

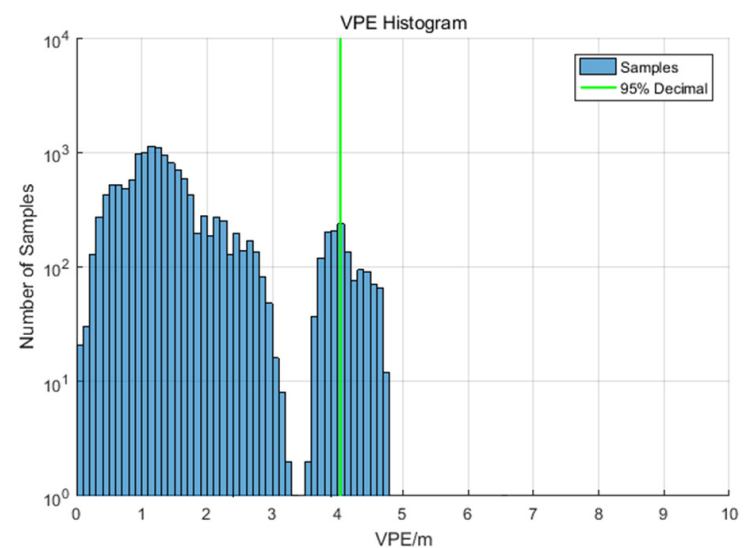

Figure 21. The VPE histogram of flight test-III. The green line in the figure is the vertical accuracy (95\%), which is $4.04 \mathrm{~m}$. 

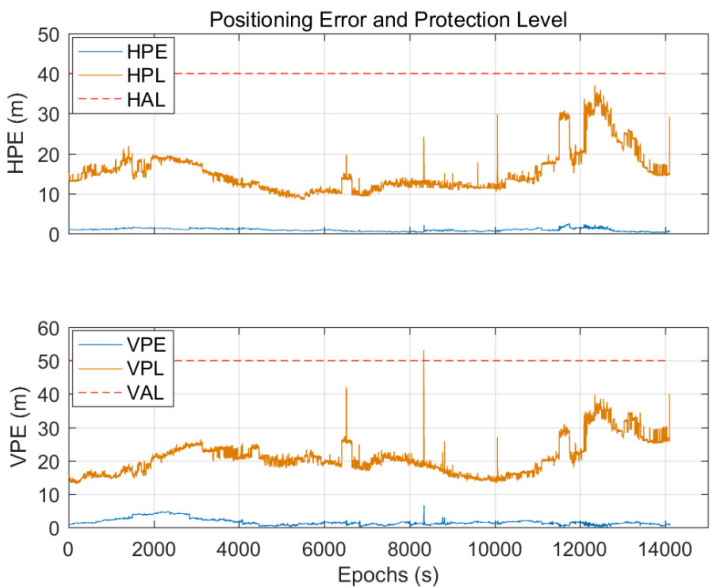

Figure 22. The PE, PL, and AL sequences of flight test-III. In both the horizontal direction (see the top panel) and the vertical direction (see the bottom panel), the PL can completely cover the PE, which means that no false alarms occurred during the test. However, there is an epoch in the bottom panel where the VPL exceeds the VAL while the VPE does not, which means that a false alarm occurred during the test.
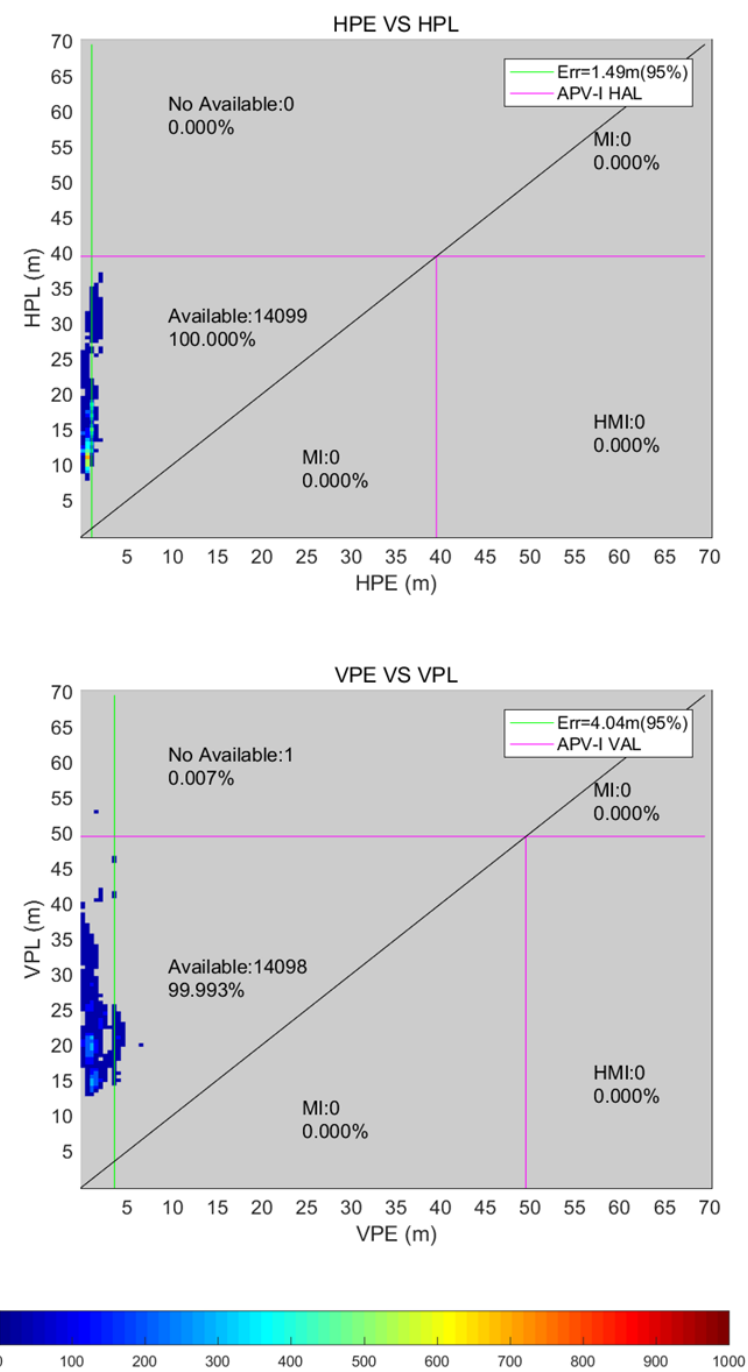

Figure 23. Stanford triangle charts for flight test-III. The top panel and the bottom panel are the horizontal Stanford chart and the vertical Stanford chart, respectively. 
Table 4 shows the statistics of the performance indicators. It can be seen from Figures 22 and 23 and Table 4 that for the flight test-III conducted on 18 September 2020, the BDSABS SF augmentation positioning accuracy meets the requirements of the civil aviation APV-I accuracy index, and the PL can completely cover the PE. No integrity risk events occurred during the test.

Table 4. BDSBAS SF performance statistics of flight test-III.

\begin{tabular}{cc}
\hline Indicators & Statistical Results \\
\hline Horizontal accuracy /m $(95 \%)$ & 1.49 \\
Vertical accuracy/m $(95 \%)$ & 4.04 \\
Minimum horizontal safety index & 11.506 \\
Minimum vertical safety index & 3.099 \\
NPA availability & $100.000 \%$ \\
NPA continuity & $100.000 \%$ \\
NPA HMI events & 0 \\
APV-I availability & $99.993 \%$ \\
APV-I continuity & $99.989 \%$ \\
APV-I HMI events & 0 \\
\hline
\end{tabular}

However, it should be noted that during the test, a false alarm event occurred in which the PL exceeded the AL and caused the system's APV-I level service to be unavailable. This reduced the availability and continuity of the APV-I level service from 100\% to $99.993 \%$ and $99.989 \%$, respectively, and caused the continuity performance to fail to meet the APV-I level requirements under the ICAO standards.

By analyzing the data, we found that this false alarm event was caused by the decrease in the number of the augmented GPS satellites available for the airborne receiver. As shown in Figure 24, in the 8834th epoch, the number of the augmented GPS satellites available for the airborne receiver suddenly decreased from nine to five, which resulted in the increase in the dilution of precision (DOP) - especially the vertical dilution of precision (VDOP), which in turn caused the VPL (vertical protection level) to exceed the VAL (vertical alarm level).

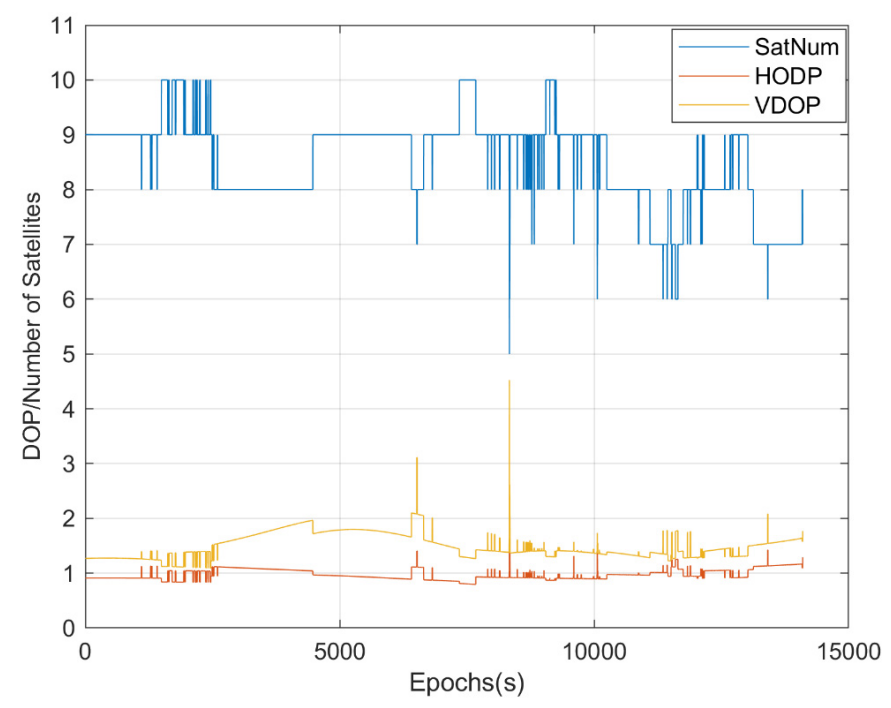

Figure 24. Available augmented satellites number and DOP sequence of the airborne receiver.

Comparing the observation data of the BDSBAS MSs in the same test period, we found that the number of the available augmented GPS satellites broadcast by BDSBAS has no abnormalities (as well as the DOP), as shown in Figure 25. Here, "BJFS" represents the MS located in Beijing, China, and "CHAN" represents the MS located in Changchun, 
China. By comparison, it can be seen that for the 8334th epoch in Figure 24 where the number of the available augmented GPS satellites decreases to five, it is completely normal in Figure 25, and the number of the available augmented GPS satellites has even exceeded nine. This indicates that the abnormality of the receiver's does not come from BDSBAS but from other environmental factors. For example, the electromagnetic interference from other airborne equipment (e.g., very high frequency (VHF), high frequency (HF), distance measuring equipment (DME), transponder (XPDR), satellite (SAT), etc.). It also suggests that in the design, manufacturing, and aviation navigation applications of SBAS receivers, special attention must be paid to strengthening the detection and protection of the aviation electromagnetic interference.

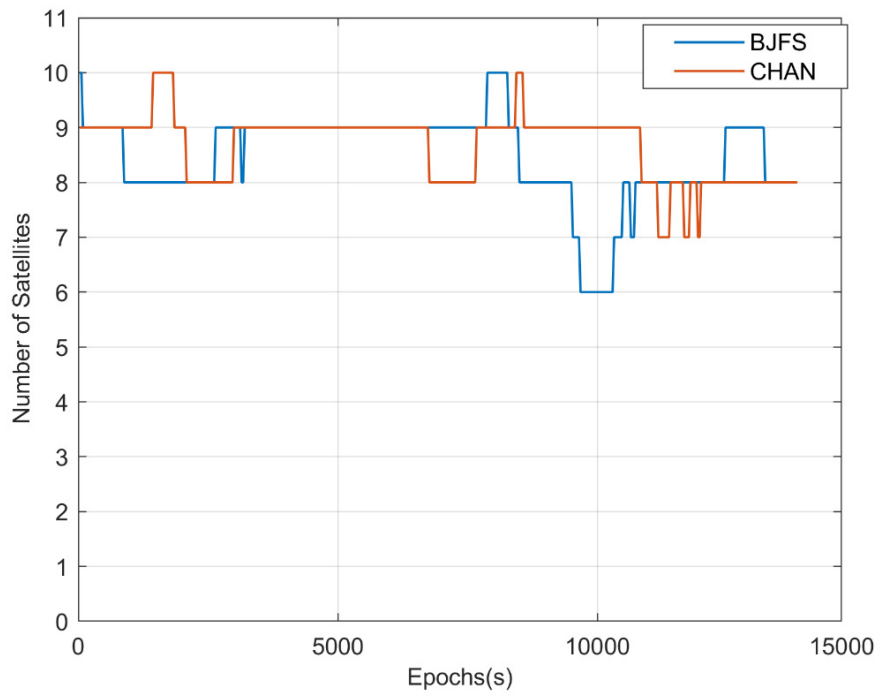

Figure 25. Number of augmented GPS satellites available for BDSBAS MSs.

\section{Conclusions}

In this paper, we described the overall situation and the construction progress of China's BDSBAS, and used the general aviation aircraft to carry out the flight test at Shenyang Caihu Airport. The BDSBAS SF service performance is evaluated and analyzed in terms of positioning accuracy, availability, continuity, and integrity.

In the flight test carried out on 17 September 2020, the take-off and landing operation was simulated with a horizontal positioning accuracy of $1.62 \mathrm{~m} \mathrm{(95 \% )}$ and a vertical positioning accuracy of $4.38 \mathrm{~m}$ (95\%). In the flight test carried out on 18 September, the take-off and landing operation and the great-circle flight operation were simulated with a horizontal positioning accuracy of $1.27 \mathrm{~m} \mathrm{(95 \% )} \mathrm{and} \mathrm{a} \mathrm{vertical} \mathrm{positioning} \mathrm{accuracy} \mathrm{of}$ $4.30 \mathrm{~m}(95 \%)$. For these two tests, the APV-I availability and continuity of the BDSBAS SF service reach $100 \%$.

In the flight test carried out on 25 September, the transition flight operation was simulated, with a horizontal positioning accuracy of $1.49 \mathrm{~m}(95 \%)$ and a vertical positioning accuracy of $4.04 \mathrm{~m}(95 \%)$. However, due to the false alarm event during the test, the APV-I availability and the continuity did not reach $100 \%$ but $99.993 \%$ and $99.989 \%$, respectively. By comparing with the data of the ground MSs, we found that there were no abnormalities in the BDSBAS service during the same period. Therefore, we believe that this false alarm event was caused by some environmental factors such as the aviation electromagnetic interference.

The vertical accuracy of each flight test was approximately $4 \mathrm{~m}$, which was due to the following reasons: (1) In September 2020, BDSBAS was in the initial testing stage, and the accuracy of orbit-clock corrections and ionospheric correction still needed to be further optimized; (2) The test location was at Shenyang, which is at the verge of BDSBAS service area. The Civil Aviation Administration of China (CAAC) will carry out the certification of 
the BDSBAS SF service. Currently, the certification plan has been completed and approved. The whole certification work will include three areas: a system technical review, service performance monitoring, and a flight operation test (which are expected to be completed in three to four years). In future, we will continue to conduct aviation tests covering more operations in order to more fully analyze and evaluate the performance of BDSBAS, including its ability to serve marginal areas. With the completion of the certification process, CAAC will approve the BDSBAS SF service to serve aviation users.

Author Contributions: Conceptualization, W.G.; original draft preparation, C.L.; methodology, Y.C. and J.L.; data analysis, B.S.; data curation and supervision, C.S.; project administration, S.X. All authors have read and agreed to the published version of the manuscript.

Funding: This work was supported in part by the National Natural Science Foundation of China (Grant Nos. 42074044 and 41974041) and in part by the Young Elite Scientist Sponsorship Program by CAST (Grant No. 2019QNRC001).

Institutional Review Board Statement: Not applicable.

Informed Consent Statement: Not applicable.

Conflicts of Interest: The authors declare no conflict of interest.

\section{References}

1. Bunce, D. Wide Area Augmentation System (WAAS) Status and History. Available online: https://www.gps.gov / multimedia/ presentations / 2014/09/ION/bunce.pdf (accessed on 19 January 2022).

2. Todd, W.; Karl, S.; Eric, A.; William, W.; Chris, H.; Robert, S. WAAS at 15. Navig. J. Inst. Navig. 2018, 65, 581-600. [CrossRef]

3. Schempp, T.; Stimmler, B. WAAS availability over the solar maximum. In Proceedings of the ION GNSS 2013, Nashville, TN, USA, 16-20 September 2013; pp. 902-911.

4. Schempp, T. WAAS Development Changes Since Commissioning. Available online: https://www.icao.int/APAC/APACRSO/GBASSBAS\%20Implementation\%20Workshop/1-4_WAAS_Development_Changes_Since_Commissioning_final\%20(T\% 20Schemmp).pdf (accessed on 19 January 2022).

5. Jason, B. Wide Area Augmentation System (WAAS)—Program Status Update. Available online: https://www.faa.gov/about/office_ org/headquarters_offices/ato/service_units/techops/navservices/gnss/library/briefings/media/WAAS_RTCA_brief_31213. pdf (accessed on 19 January 2022).

6. Lawrence, D. FAA WAAS Update. Available online: https://www.gps.gov/multimedia/presentations/2015/03/munich/ lawrence1.pdf (accessed on 19 January 2022).

7. Lawrence, D. FAA Navigation Programs Update. Available online: https://www.gps.gov/cgsic/meetings/2019/lawrence.pdf (accessed on 19 January 2022).

8. Walter Kee, C.; Walter, T.; Kee, C.; Chao, Y.C.; Tsai, Y.J.; Peled, U.; Ceva, J.; Barrows, A.K.; Abbott, E.; Powell, D.; et al. Flight Trials of the Wide-Area Augmentation System (WAAS). In Proceedings of the ION GPS 1994, Salt Lake City, UT, USA, $20-23$ September 1994.

9. European GNSS Agency (EGA). EGNOS Open Service (OS) Service Definition Document Issue 2.3. Available online: https: //www.gsc-europa.eu/sites/default/files/sites/all/files/egnos_os_sdd_in_force.pdf (accessed on 19 January 2022).

10. EGA. EGNOS Safety of Life (SOL) Service Definition Document Issue 3.4. Available online: https://www.gsc-europa.eu/ sites / default/files/sites/all/files/egnos_sol_sdd_in_force.pdf (accessed on 19 January 2022).

11. EGA. EGNOS Data Access Service (EDAS) Service Definition Document Issue 2.2. Available online: https:/ / egnos-user-support. essp-sas.eu/new_egnos_ops/sites/default/files/documents/egnos_edas_sdd_in_force.pdf (accessed on 19 January 2022).

12. Thales Alenia Space. EGNOS Status. Available online: https://www.icao.int/APAC/APAC-RSO/GBASSBAS\%20 Implementation\%20Workshop/1-5_EGNOS\%20Status_final\%20(G\%20COMELLI).pdf (accessed on 19 January 2022).

13. Celestino, U. EGNOS Status and Plans. Available online: https://www.icao.int/MID/Documents/2016/ACAC-ICAO\%20 GNSS/EC\%20Rabat\%20EGNOS\%20status\%20and\%20plans_final.pdf\#search=EGNOS (accessed on 19 January 2022).

14. Krasuski, K.; Wierzbicki, D. Monitoring Aircraft Position Using EGNOS Data for the SBAS APV Approach to the Landing Procedure. Sensors 2020, 20, 1945. [CrossRef] [PubMed]

15. Saito, S. MSAS System Development. Available online: https://www.icao.int/APAC/APAC-RSO/GBASSBAS\%20 Implementation\%20Workshop/1-6_MSAS\%20System\%20Development_Rev2\%20(S\%20Saito).pdf (accessed on 19 January 2022).

16. Cabinet Office. Quasi-Zenith Satellite System Performance Standard (PS-QZSS-001). Available online: https:/ / qzss.go.jp/en/ technical/download/pdf/ps-is-qzss/ps-qzss-001.pdf (accessed on 19 January 2022).

17. Sakai, T.; Tashiro, H. MSAS Status. In Proceedings of the Meeting of the Satellite Division of the Institute of Navigation, Savannah, GA, USA, 22-25 September 2013; pp. 2343-2360.

18. Sakai, T. The status of dual-frequency multi-constellation SBAS trial by Japan. In Proceedings of the International Symposium on GNSS, Hong Kong, China, 8-10 December 2017. 
19. Schemmp, T. GAGAN Regional Service Availability. Available online: https://www.icao.int/APAC/APAC-RSO/GBASSBAS\% 20Implementation\%20Workshop/3-7_GAGAN_Regional_Service_Availability\%20(T\%20Schemmp).pdf (accessed on 19 January 2022).

20. Airports Authority of India (AAI). System Development-GAGAN. Available online: https://www.icao.int/APAC/APAC-RSO/ GBASSBAS\%20Implementation\%20Workshop/1-7_System\%20Development-GAGAN_final\%20(M\%20Rao).pdf\#search=GAGAN (accessed on 19 January 2022).

21. ICAO. Status Update of GNSS Activities in India. Available online: https://www.icao.int/APAC/Meetings/2016\%20ISTF6/IP0 5_IND \%20AI.3\%20-\%20Status\%20update\%20of\%20GNSS\%20activities.pdf\#search=GAGAN (accessed on 19 January 2022).

22. ICAO. GAGAN Status and Expansion. Available online: https://www.icao.int/APAC/Meetings/2017\%20APANPIRG28/IP\%20 06,\%20AI\%203.4\%20-\%20GAGAN\%20Ver\%201.0.pdf\#search=GAGAN (accessed on 19 January 2022).

23. Revnivykh, I. GLONASS and SDCM Status and Development. Available online: http://www.unoosa.org/documents/pdf/icg/ 2019/icg14/03.pdf (accessed on 19 January 2022).

24. ICAO. Status of Korean SBAS Program. Available online: https://www.icao.int/APAC/Meetings/2017\%20PBNICG4/IP12 Status\%20of\%20Korean\%20SBAS\%20Program_updated.pdf\#search=KASS (accessed on 19 January 2022).

25. Lee, E. System Development-KASS. Available online: https://www.icao.int/APAC/APAC-RSO/GBASSBAS\%20Implementation\% 20Workshop/1-8_KASS_Development_Status_final\%20(E\%20Lee).pdf\#search=KASS (accessed on 19 January 2022).

26. Choi, J. Regulation for KASS Certification. Available online: https://www.icao.int/APAC/APAC-RSO/GBASSBAS\%20 Implementation \%20Workshop/2-6_[final]\%20ICAO\%20workshop \%20presentation \%20(Y\%20Choi).pdf\#search=KASS (accessed on 19 January 2022).

27. China Satellite Navigation Office (CSNO). The Application Service Architecture of BeiDou Navigation Satellite System (Version 1.0). Available online: http:/ / www.beidou.gov.cn/xt/gfxz/201912/P020191227333024390305.pdf (accessed on 19 January 2022).

28. ICAO. The Development Plan of the BeiDou Satellite-Based Augmentation System (BDSBAS). Available online: https: //www.icao.int/APAC/Meetings/2017\%20CNSSG21/WP16_China\%20AI.5\%20-\%20Rev\%20-\%20Beidou\%20Augumentation\% 20System.pdf\#search=BDSBAS (accessed on 19 January 2022).

29. ICAO. DFMC SBAS SARPs: Part A Version 2.2. Available online: https://www.icao.int/airnavigation/Documents/NSP5 _Report\%20on\%20Agenda\%20Item\%202.APPENDIX\%20A1\%20-\%20DFMC\%20SBAS\%20SARPS\%20Part\%20A.pdf (accessed on 19 January 2022).

30. CSNO. Development of the BeiDou Navigation Satellite System (Version 4.0). Available online: http://www.beidou.gov.cn/xt/ gfxz/201912/P020191227430565455478.pdf (accessed on 19 January 2022).

31. GPS PRN Coordination Office (PRNCO). L1 C/A PRN Code Assignments. Available online: https://www.gps.gov/technical/ prn-codes/L1-CA-PRN-code-assignments-2020-Oct.pdf (accessed on 19 January 2022).

32. Liu, C.; Gao, W.; Shao, B.; Lu, J.; Wang, W.; Chen, Y.; Su, C.; Xiong, S.; Ding, Q. Development of BeiDou satellite-based augmentation system. Navigation 2021, 68, 405-417. [CrossRef]

33. Radio Technical Commission for Aeronautic (RTCA). Minimum Operational Performance Standards (MOPS) for Global Positioning System/Satellite-Based Augmentation System Airborne Equipment (Standard), Washington, DC, USA. 2016. Available online: https: / / my.rtca.org/NC_Product?id=a1B3600000211rIEAQ (accessed on 19 January 2022).

34. Cao, Y.; Hu, X.; Wu, B. The Wide Area Difference System for the Regional Satellite Navigation System of Compass. Sci. China Phys. Mech. Astron. 2012, 55, 1307-1315. [CrossRef]

35. ICAO. International Standards and Recommended Practices (SARPs) Annex 10-Aeronautical Telecommunications, 7th ed.; ICAO: Montreal, QC, Canada, 2018; Volume I. 